\title{
Landslide Susceptibility Mapping Using Single Machine Learning Models: A Case Study from Pithoragarh District, India
}

\author{
Trinh Quoc Ngo, ${ }^{1}$ Nguyen Duc Dam, ${ }^{1}$ Nadhir Al-Ansari ${ }^{10},{ }^{2}$ Mahdis Amiri, ${ }^{3}$ \\ Tran Van Phong, ${ }^{4}$ Indra Prakash $\mathbb{D},{ }^{5}$ Hiep Van Le, ${ }^{1}$ Hanh Bich Thi Nguyen, ${ }^{1}$ \\ and Binh Thai Pham $\mathbb{D}^{1}$ \\ ${ }^{1}$ University of Transport Technology, Hanoi 100000, Vietnam \\ ${ }^{2}$ Department of Civil, Environmental and Natural Resources Engineering, Lulea University of Technology, Lulea 97187, Sweden \\ ${ }^{3}$ Department of Watershed \& Arid Zone Management, Gorgan University of Agricultural Sciences \& Natural Resources, \\ Gorgan 4918943464, Iran \\ ${ }^{4}$ Institute of Geological Sciences, Vietnam Academy of Science and Technology (VAST), 84 Chua Lang, Dong Da, Hanoi, Vietnam \\ ${ }^{5} D D G(R)$ Geological Survey of India, Gandhinagar 382010, India
}

Correspondence should be addressed to Nadhir Al-Ansari; nadhir.alansari@ltu.se and Binh Thai Pham; binhpt@utt.edu.vn

Received 23 March 2021; Revised 17 June 2021; Accepted 13 July 2021; Published 23 July 2021

Academic Editor: Luís C. Neves

Copyright (c) 2021 Trinh Quoc Ngo et al. This is an open access article distributed under the Creative Commons Attribution License, which permits unrestricted use, distribution, and reproduction in any medium, provided the original work is properly cited.

\begin{abstract}
Landslides are one of the most devastating natural hazards causing huge loss of life and damage to properties and infrastructures and adversely affecting the socioeconomy of the country. Landslides occur in hilly and mountainous areas all over the world. Single, ensemble, and hybrid machine learning (ML) models have been used in landslide studies for better landslide susceptibility mapping and risk management. In the present study, we have used three single ML models, namely, linear discriminant analysis (LDA), logistic regression (LR), and radial basis function network (RBFN), for landslide susceptibility mapping at Pithoragarh district, as these models are easy to apply and so far they have not been used for landslide study in this area. The main objective of this study is to evaluate the performance of these single models for correctly identifying landslide susceptible zones for their further application in other areas. For this, ten important landslide affecting factors, namely, slope, aspect, curvature, elevation, land cover, lithology, geomorphology, distance to rivers, distance to roads, and overburden depth based on the local geoenvironmental conditions, were considered for the modeling. Landslide inventory of past 398 landslide events was used in the development of models. The data of past landslide events (locations) was randomly divided into a 70/30 ratio for training (70\%) and validation (30\%) of the models. Standard statistical measures, namely, accuracy (ACC), specificity (SPF), sensitivity (SST), positive predictive value (PPV), negative predictive value (NPV), Kappa, root mean square error (RMSE), and area under the receiver operating characteristic curve (AUC), were used to evaluate the performance of the models. Results indicated that the performance of all the models is very good (AUC > 0.90) and that of the LR model is the best (AUC $=0.926$ ). Therefore, these single ML models can be used for the development of accurate landslide susceptibility maps. Our study demonstrated that the single models which are easy to use and can compete with the complex ensemble/hybrid models can be applied for landslide susceptibility mapping in landslide-prone areas.
\end{abstract}

\section{Introduction}

Landslides are the most common natural disasters in the hilly and mountainous areas all over the world. Landslides are the downward movement of rock mass/groundmass/ rock blocks by gravity [1]. Rainfall, earthquakes, and slope excavation are triggering factors for the occurrence of landslides [2]. Some of the influencing factors of landslides include the topography, geology, hydrology, and land use pattern of the area [3]. In the recent decade, landslide events have increased in both magnitude and frequency due to climate change effect reflected in rainfall patterns $[4,5]$. 
Therefore, it is desirable to identify landslide-susceptible zones for better landslide management and disaster reduction [6].

Nowadays, single, ensemble, and hybrid machine learning (ML) methods are used in conjunction with the remote sensing (RS) and geographic information system (GIS) for landslide susceptibility studies [7-11]. Some of the single methods include support vector machine (SVM), kernel logistic regression (KLR), logistic model tree (LMT), classification and regression trees (CRT), function trees (FT), alternative decision tree (ADT), artificial neural Network (ANN), Naïve Bayes (NB), Fisher's linear discriminant function (FLDF), reduced error pruning trees (REPT), decision tree (DT), neurofuzzy (NF), and adaptive regression splines (ARS). In addition, many researchers have used ensemble and hybrid ML techniques, which are a combination of ensembles such as Bagging, Dagging, MultiBoost, AdaBoost, and Random Forest (RF), as well as optimization algorithms such as biogeography-based optimization (BBO), genetic algorithm (GA), gray wolf optimizer (GWO), and particle swarm optimization (PSO) with single ML algorithms, for landslide susceptibility mapping and prediction [12-14]. These methods are being used for better land use planning and infrastructure development besides the development of early warning systems $[15,16]$. There is a need for reevaluation of single ML models to prove their ability to produce good landslide susceptibility maps for their application in landslide-prone areas as they are simple to use in comparison to ensemble and hybrid models. Literature survey indicates that some of the single ML algorithms can compete with complex ensemble and hybrid models and can be used for the prediction of landslide susceptibility [17-19]. Therefore, in the present study, we have used single linear discriminant analysis (LDA), logistic regression (LR), and radial basis function network (RBFN) methods for the landslide susceptibility mapping at Pithoragarh district of Uttarakhand state, India. Landslide influencing factors, namely, slope, aspect, curvature, elevation, land cover, lithology, geomorphology, distance to rivers, distance to roads, and overburden depth, were used for landslide susceptibility modeling. Distance to faults/ lineaments has not been considered in this study as a separate factor because distance from rivers which are structurally controlled (faults/lineaments) has been considered in the present model study to avoid repetition. Moreover, rainfall has not been considered in the model study as most of the landslides in the area occur during rains; thus, it has been considered as a triggering factor.

Popular statistical measures such as accuracy (ACC), specificity (SPF), sensitivity (SST), positive predictive value (PPV), negative predictive value (NPV), Kappa index, root mean square error (RMSE), and area under the receiver operating characteristic curve (AUC) were used for the evaluation and comparison of the performances of the studied models. The main objective of the study is to select the best single model for accurate and reliable landslide susceptibility mapping in the hilly and mountainous areas. Weka and GIS software have been used for the data processing and modeling.

\section{Methods Used}

2.1. Linear Discriminant Analysis (LDA). LDA is known as a feature selection method that optimizes the number of factors used for modeling or classification processes. One of the functions of the LDA model is to create an optimal space such that the data used in this space has the most distinctive information [20]. In the ML algorithm, the purpose of reducing the dimensions is to reduce one dimension of a $d$-dimensional data predicted by a $k$-dimensional subset, when $k \leq d$. The purpose of this step is to increase the computed output/yield while reducing error/ noise and information abundances and protecting more information about the genuine data [21]. Dimension reduction can be done by searching for a linear transformation matrix $W \in R^{n \times d}, d \leq n$, so that the dispersion/ scattering distance among the categories is maximum and at the same time the dispersion/scattering is minimized within the category. In other words, LDA is a monitoring algorithm [22] which calculates the linear differentiator by maximizing the interval between classes and minimizing the interval between the categories. The distribution matrix in class $S_{b}$ and the distribution matrix within class $S_{W}$ can be given by

$$
\begin{gathered}
S_{b}=\frac{1}{N} \sum_{i=1}^{c} N_{i}\left(\bar{x}_{i}-\bar{x}\right)\left(\bar{x}_{i}-\bar{x}\right)^{T}, \\
S_{W}=\frac{1}{N} \sum_{i=1}^{c} \sum_{s=1}^{N_{i}}\left(x^{i s}-\bar{x}_{i}\right)\left(x^{i s}-\bar{x}_{i}\right)^{T} .
\end{gathered}
$$

LDA model then solves the optimization problem as follows:

$$
\frac{\operatorname{Max}_{W} \operatorname{tr}\left(W^{T} S_{b} w\right)}{\operatorname{tr}\left(W^{T} S_{W} w\right)}
$$

where $\operatorname{tr}$ and $T$ are the effective action and relocation of a matrix, respectively.

2.2. Logistic Regression (LR). LR is a supervised learning algorithm mainly used for binary classification. In landslide modeling using this method, the presence of landslides is considered as " 1 " and the absence of landslides is considered as " 0 " [23]. When LR is fitted for a regression or classification problem, it first creates a valuable practice. Afterwards, the optimum model variables are recognized via a repetitive nonlinear optimization way [24]. The model quality test is finally over. The divination practice is reelevated to the sigmoid subordinate [25]:

$$
S(x)=\frac{1}{1+e^{-x}}
$$

where $x$ is an influencing factor.

The forecast subordinate of logistic regression is derived by the following equation: 


$$
\begin{aligned}
g_{\omega}(x) & =S\left(\omega^{T} x\right) \\
& =\frac{1}{1+e^{-\omega T x}}
\end{aligned}
$$

where $\omega$ denotes the weights assigned to the input variables.

The disadvantage subordinate is determined as follows:

$$
L(\omega)=\frac{1}{m} \sum\left(y_{i} \log g_{\omega}\left(x_{i}\right)+\left(1-y_{i}\right) \log \left(1-g_{\omega}\left(x_{i}\right)\right)\right),
$$

where $m$ is the extent of the data, $x_{\mathrm{i}}$ is the specific value of every instance data point, and $y_{i}$ is the class tag of each data instance. From the previous equation, it can be shown that the basic concept of logistic regression mathematics is the inherent logarithm of the unique proportion [26, 27].

The regression variable can be $\omega$, which understates the detriment performance achieved by a steep descending method [28]. The gradient reduction algorithm is used to discover the optimal local resolution of a subordinate in ML. In the gradient reduction method, the section extracted from the senior disadvantage subordinate can be generated as follows:

$$
\frac{\partial L(\omega)}{\partial \omega_{i}}=-\frac{1}{m} \sum\left(y^{i}-g_{\theta}\left(x_{i}\right)\right) x_{j}^{i} .
$$

The parameter can then be updated based on the negative aspect of the variable as

$$
\left.\omega_{j}=\omega_{j}+\frac{1}{m} \sum y_{i}-g_{m}\left(x^{i}\right)\right) x_{j}^{i}
$$

By the learning price/rate $\eta$, the variable $\omega$ can be used:

$$
\omega_{j}:=\omega_{j}-\eta \partial \frac{L_{i}}{\partial \omega_{j}} .
$$

2.3. Radial Basis Function Network (RBFN). RBFN is a simulator that consists of radial subordinates [29]. RBFN can be applied to achieve performance approximation and pattern recognition $[30,31]$. A radial subordinate is appointed as a subordinate $\varphi$ which is radially isochronous about certain points $\mu$ in the input area. One popular kind of radial subordinates is Gaussian subordinates [32]; for example,

$$
\varphi(x, \mu)=\exp (-\gamma\|x-\mu\| 2)
$$

where $\gamma>0$ is a variable and $\|$.$\| defines the Euclidean rule.$ The point $\mu \in R^{p}$ is easily named the capital of the principal subordinate. The radiant foundation subordinate way supported $r$ radiant subordinate with various focused $\mu_{1}, \ldots \mu_{r}$, where $r$ is elected via the user which is usually much shorter than the training dataset measure $n$ [33]. One public approach to specify suitable centers is by using a category analysis way, for example, $k$-means $[34,35]$. Exploiting $k$-means, one can divide the training dataset $T$ into $r$ disintegrate cluster, in which every cluster has a linked centroid that can be thought of as an archetype of the cluster. It makes sense to use these centroids as the focuses of the analogized foundation subordinates. Hence, RBFN approximates $v(x)$ as

$$
\widehat{v}(x)=\sum r j=1 w_{j} \varphi\left(x, \mu_{j}\right)
$$

where $w_{1}, \ldots, w_{r}$ are variables. It is suitable to present the vector $W=\left(w_{1}, \ldots, w_{r}\right)^{T}$ and the $n \times r$ matrix $\Phi$ with origins $\Phi(i, j)=\varphi\left(x_{\mathrm{i}}, \mu_{j}\right)$. The variable vector $W$ is generally specified as the vector that minimizes the error subordinate.

$$
E=\frac{1}{2} \sum n k=1(v(x)-v(x))^{2} .
$$

An analytic statement for the optimal ratio vector is [36]

$$
W=\Phi N(T),
$$

where $\Phi^{\dagger}$ is the pseudoreverse of $\Phi$.

A particular instance exists when $n=r$, as where there is $n$, foundation operations with focus $\mu_{j}=x_{j}$. In this case, the optimal weighting vector is specified via $W=\Phi^{-1} \cdot N$ (T).

RBFN is particularly well adapted to set very great training datasets which are supported by cluster study.

2.4. Validation Methods. Validation is a crucial step in every modeling project [37-39]. In this study, we used the receiver operating characteristic (ROC) curve and a set of statistical indices for model validation. These metrics are briefly described as follows.

2.4.1. Receiver Operating Characteristic (ROC) Curve. One of the popular methods for evaluating the output of landslide susceptibility models is the ROC curve. ROC curve is one of the most common methods for evaluating the performance of methods and algorithms used for spatial modeling $[40,41]$. The numerical value of the area under the ROC curve (AUC) varies between 0 and 1 , which is quantitatively used for the validation and comparison of the models. Higher AUC values indicate higher model performance and the ability for capturing the general trend of landslide occurrences as well as for predicting future landslides [42-45].

2.4.2. Statistical Indices. Other evaluation metrics used in the present study to select the best model were ACC, SPF, SST, PPV, NPV, Kappa index, and RMSE that have widely been used in the literature [46-50]. SST is the ratio of landslide pixels that are correctly classified as landslide events. SPF refers to pixels that are correctly classified and referred to as nonslip pixels [48]. These indicators are calculated based on true positive (TP), true negative (TN), false positive (FP), and false negative (FN) using the following equations: 


$$
\begin{aligned}
& \mathrm{SST}=\frac{\mathrm{TP}}{(\mathrm{TP}+\mathrm{FN})}, \\
& \mathrm{SPF}=\frac{\mathrm{TN}}{(\mathrm{TN}+\mathrm{FP})} .
\end{aligned}
$$

ACC is a statistical index that measures the overall accuracy of the classification process by calculating the ratio of landslide and nonlandslide pixels that are correctly classified:

$$
\mathrm{ACC}=\frac{(\mathrm{TP}+\mathrm{TN})}{(\mathrm{TP}+\mathrm{FN}+\mathrm{FP}+\mathrm{TN})}
$$

PPV is the ratio of landslide sensitivity pixels that correctly classify all pixels classified as landslide pixels. NPV is the ratio of the pixels that are properly classified as nonlandslide.

$$
\begin{aligned}
\mathrm{PPV} & =\frac{\mathrm{TP}}{\mathrm{TP}+\mathrm{FP}}, \\
\mathrm{NPV} & =\frac{\mathrm{TN}}{\mathrm{TN}+\mathrm{FN}},
\end{aligned}
$$

where TP displays the correctly grouped landslide pixels, TN indicates the correctly classified nonlandslide pixels, FP is the number of pixels that are wrongly classified, and $\mathrm{FN}$ is the number of pixels that are wrongly classified.

In addition to the indices described, the reliability of models can be tested using Kappa. This metric is a strong and trustworthy metric for the classification system because it considers the probability of compromise/agreement occurring randomly. The Kappa indicator is computed as follows:

$$
\begin{aligned}
\text { Kappa }= & (\mathrm{TP}+\mathrm{TN})-(\mathrm{TP}+\mathrm{FNTP}+\mathrm{FP}+\mathrm{FP}+\mathrm{TNFN}+\mathrm{TN}) 1 \\
& -(\mathrm{TP}+\mathrm{FNTP}+\mathrm{FP}+\mathrm{FP}+\mathrm{TNFN}+\mathrm{TN}) .
\end{aligned}
$$

RMSE was also used to measure the difference between observations and predictions, known as modeling error [51], which is calculated as follows:

$$
\text { RMSE }=\sqrt{\frac{\sum_{i=1}^{n}\left(y_{\mathrm{obs}}-y_{\mathrm{pre}}\right)^{2}}{N}},
$$

where $N$ is the number of landslide samples, $y_{\mathrm{obs}}$ is the observed value of sample $i$, and $y_{\text {pre }}$ is the predicted value of sample $i$.

\section{Study Area}

Pithoragarh District $\left(30.0^{\circ} \mathrm{N}, 80.15^{\circ} \mathrm{E}\right)$ is located in Uttarakhand State, Northern India (Figure 1). Physiographically, the area consists of numerous NW-SE-aligned curvilinear hills. The rivers of the Ganga system, namely, Girthi, Keogad, Kali, Gori, Dhauli, Kutiyangti, Sarju, and Ramganga flowing along the periphery and through the district formed rugged topography and deep valleys. The study area is dissected by numerous faults/thrusts and shears. The district is bounded on the northern side by the

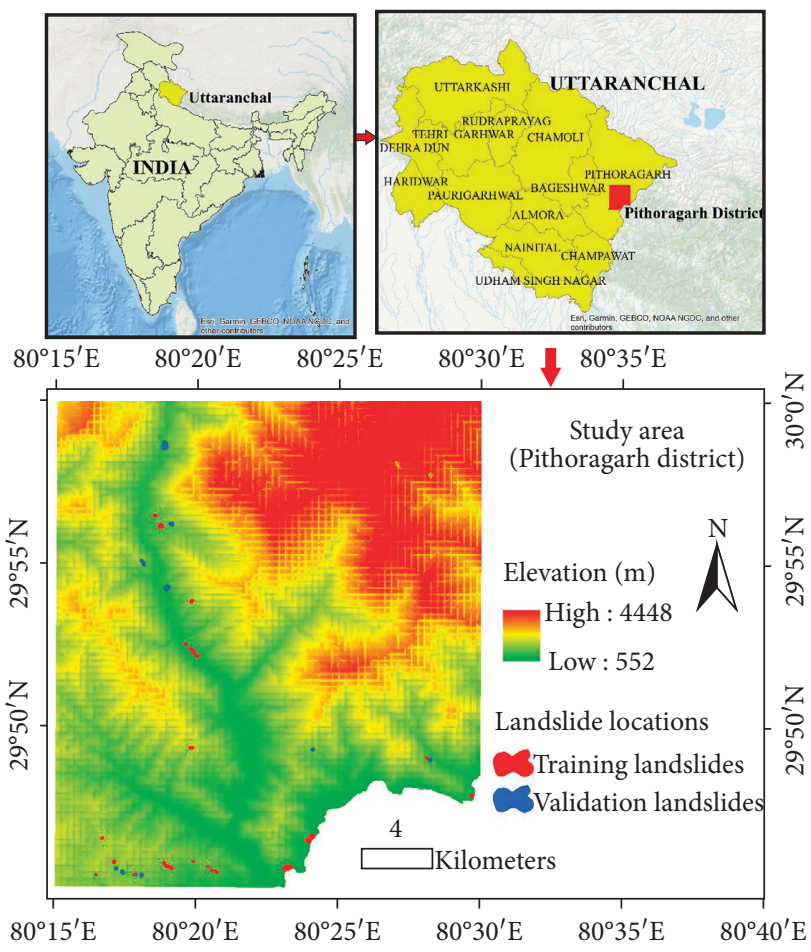

FIgURE 1: Location of the study area and historical landslides.

Main Central Thrust (MCT) and on the southern side by North Almora Thrust (NAT). The area is seismotectonically active (GSI 2000). The main rock types in this area belong to the Garhwal Group of Mesoproterozoic age (1600-1000 Ma). These rock types include quartzite, phyllite, schist, limestone, dolomitic limestone, slate, and also metavolcanics and intrusive amphibolites at places. This district has extreme variation in temperature from below zero (high hills above $3,500 \mathrm{~m}$ remain covered with snow) to $40^{\circ} \mathrm{C}$ (river gorges). The rainy season in this area extends from mid-June to midSeptember. The annual average rainfall is about 360 centimeters at lower elevation.

\section{Data Used}

4.1. Landslide Inventory. Accurate knowledge of problem influencing variables and corresponding data is required for dealing with practical engineering problems [52-55]. Identification and collection of landslide events and their past and current locations using time series Google Earth and satellite images [56] in conjunction with field surveys and reports are required to develop a landslide inventory map [14]. The collection of geospatial information of landslides is very important and fundamental in the spatial modeling process [12]. In this study, we have used data of 398 landslide events extracted from the Geological Survey of India report (http://www.portal.gsi.gov.in) and by the interpretations of Google Earth images [57]. Landslide polygons delineated were represented by points on the maps for the modeling purpose. These landslide locations (398 points) were randomly divided in the ratio of $70 / 30$ as a training (70\% points: 261 ) and testing/validation (30\% points: 137$)$ 
data, respectively, based on the experience of the authors and other researchers in the field of ML modeling $[58,59]$. The majority of the landslides in the study area are of debris flow and rock fall types (Figure 2).

4.2. Landslide Influencing Factors. One of the important issues in the process of spatial modeling of landslide susceptibility is the selection of the landslide influencing factors and the preparation of the thematic maps of the features. There is no uniform rule for the selection of landslides influencing factors [60, 61]; thereby these factors are selected based on previous similar studies and knowledge of the topography, geology, and geoenvironmental conditions of the study area $[62,63]$. Anthropogenic activities such as the construction, infrastructure development, and land use changes can disturb the natural stability of the ground mass causing landslides in the area. Natural phenomena such as earthquakes, floods, and heavy rains are some of the main triggering factors for the occurrence of landslides. In this study, an Aster DEM with $30 \mathrm{~m}$ resolution (https:// earthexplorer.usgs.gov) was used for the development of the topographic thematic factors [64]. Figure 3 represents thematic maps of the landslide influencing factors and Table 1 represents the relationships between landslides and the influencing factors using the frequency ratio (FR) method as described by Lee and Pradhan [65].

Brief descriptions of the ten influencing factors (slope, aspect, curvature, elevation, geomorphology, land cover, distance to roads, distance to rivers, lithology, and overburden depth) considered in this study are described as follows.

4.2.1. Slope. Slope is an effective factor in landslide susceptibility modeling due to its significant effects on material sliding and water flow due to gravitational effect [66]. Moderate and higher slopes are more vulnerable to landslides. Natural slopes in the area are not uniform from lower elevation to higher elevation and also laterally as they depend on many factors such as geology, structure, soil, drainage, and erosion. Therefore, They have been classified into five groups based on the natural break method using GIS software from DEM for better site representation of this factor in the modeling (Figure 3). The highest weight $(\mathrm{FR}=1.40)$ of landslides occurrence was observed on the areas with slope degrees of $47-88.677^{\circ}$ (Table 1).

4.2.2. Aspect. Aspect is a subset of topographic factors which is closely related to sunlight and precipitation falling on different faces of slopes [67]. This factor has also an effect on the hydrological process, evaporation, and transpiration and also on weathering processes and vegetation [68]. In this study, an aspect map was generated from DEM and grouped into nine categories (Figure 3). The highest weight $(\mathrm{FR}=1.57)$ of landslides occurrence was observed on the southern slopes (Table 1).
4.2.3. Curvature. Curvature is one of the morphometric factors which affects water flow and erosion of the ground causing landslide $[68,69]$. Curvature map of the study area was divided into three classes: flat $(\mathrm{FR}=3.57)$, convex $(\mathrm{FR}=1.24)$, and concave $(\mathrm{FR}=0.80)$ curvatures, respectively (Table 1 and Figure 3).

4.2.4. Elevation. Elevation affects local climate and air/ weather conditions of regions [70] and is an important factor for describing the other factors, such as landform, rainfall, land use type, human activities, vegetation type and distribution, and soil weathering conditions as well as the rate of erosion which affects landslides [71, 72]. Generally, rainfall and weathering occur at lower to moderate elevations. At higher elevations, snow falls and rocks are less weathered. The elevation map of the study area was produced from DEM which was then divided into nine classes based on the natural break method (Figure 3). Most landslides occurred in an altitude class between 551 and $1000 \mathrm{~m}$ with an FR value of 5.46 (Table 1).

4.2.5. Geomorphology. Geomorphology of the area describes the relief features of the Earth and can significantly control the landslide occurrences $[54,73,74]$. This factor map was extracted from the GSI report, checked from the DEM and Google Earth images, and classified into twelve geomorphological units (Figure 3). Among the geomorphology feature "intermontane plateau" had the highest FR of 8.91 (Table 1).

4.2.6. Land Cover. Land cover, which consists of vegetation, barren land, and built-up areas [75], affects the landslide susceptibility of the area $[76,77]$. This map was prepared from the satellite images in conjunction with Google Earth images and classified into eight classes (Figure 3). Most of the landslides occurred in sparsely vegetated $(F R=5.35)$ and wasteland $(\mathrm{FR}=3.51)($ Table 1$)$.

4.2.7. Distance to Roads. Road construction and roadside excavation can destroy natural slope stabilities, thereby affecting landslide occurrences [78-80]. In this study, road networks were digitized from Google Earth images and buffered into different classes (Figure 3). Most of the landslides in the study are located at $0-100 \mathrm{~m}$ distance from the roads with an FR value of 12.62 (Table 1).

4.2.8. Distance to Rivers. Distance to rivers is one of the important factors related to adjacent ground slope erosion and saturation causing landslides [81-83]. The drainage in the area is structurally controlled (faults/lineaments). The river map of the study area was generated from DEM using the flow direction tool of GIS and Google Earth images and buffered into six classes (Figure 3). Most of the landslides in the study are located at $0-100 \mathrm{~m}$ distance from the rivers with an FR value of 8.19 (Table 1). 


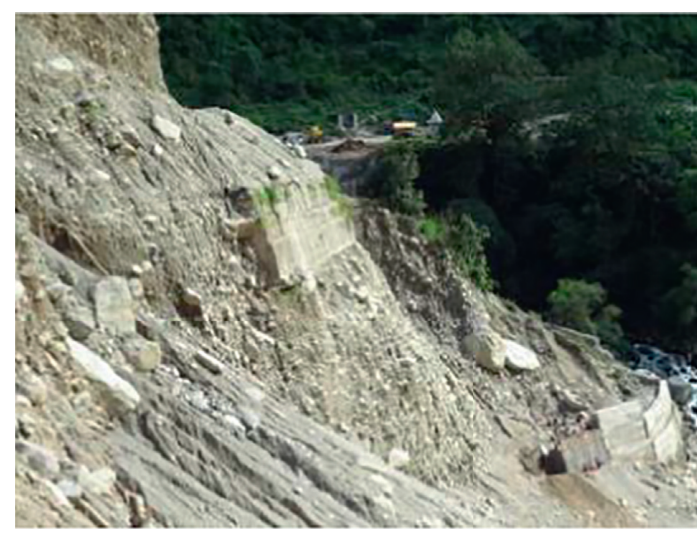

(a)

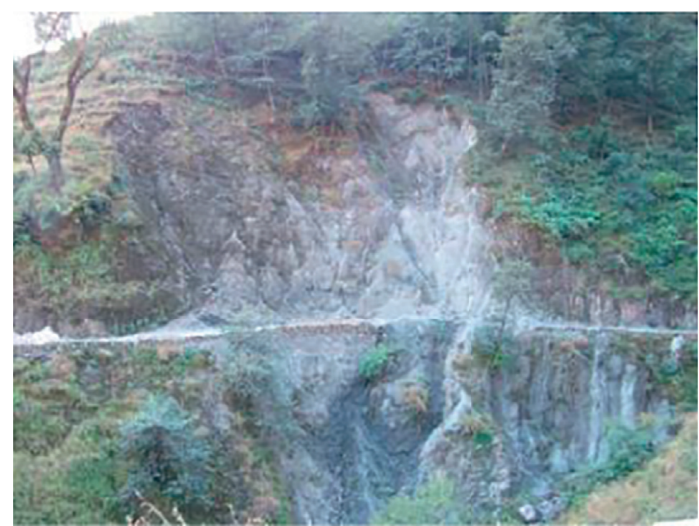

(c)

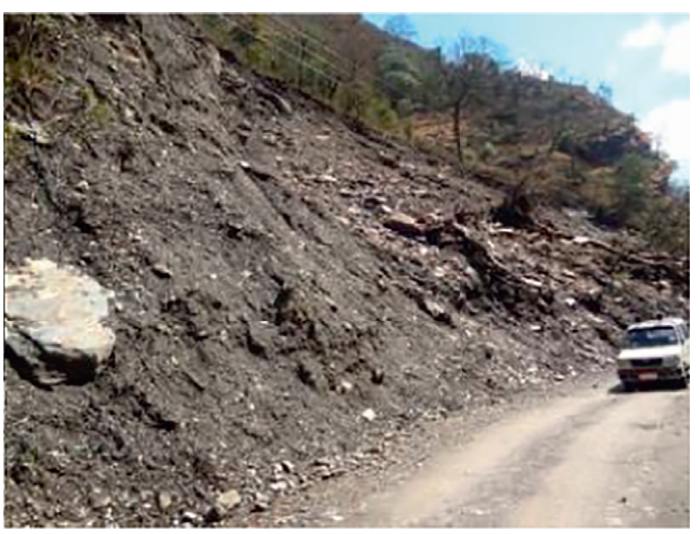

(b)

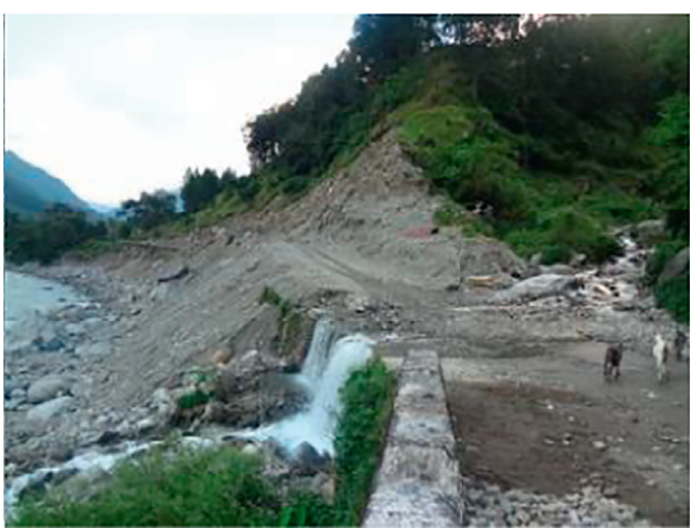

(d)

FIGURE 2: Landslide photos of the study area (source: http://www.portal.gsi.gov.in).
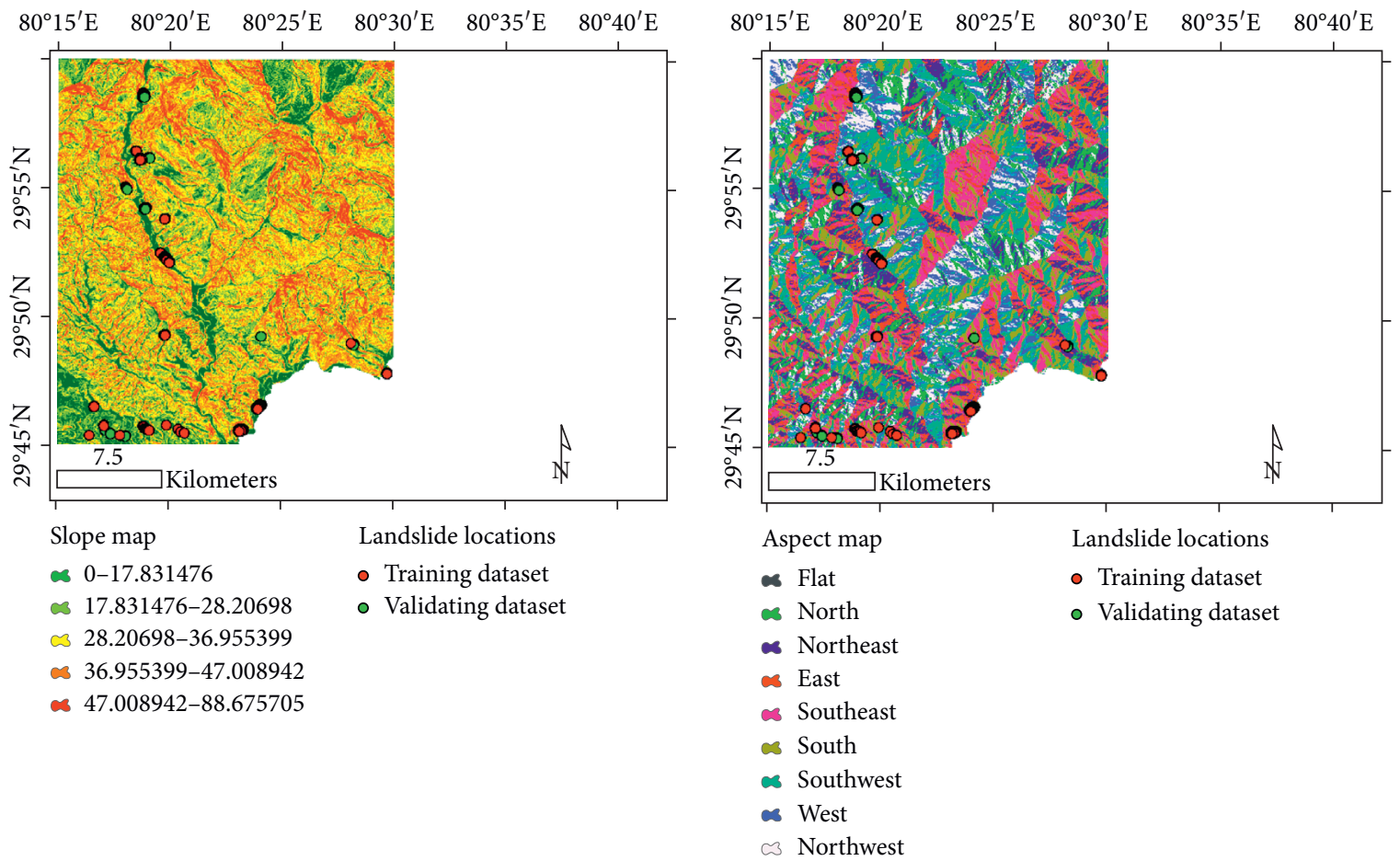

(a)

FIgURE 3: Continued. 

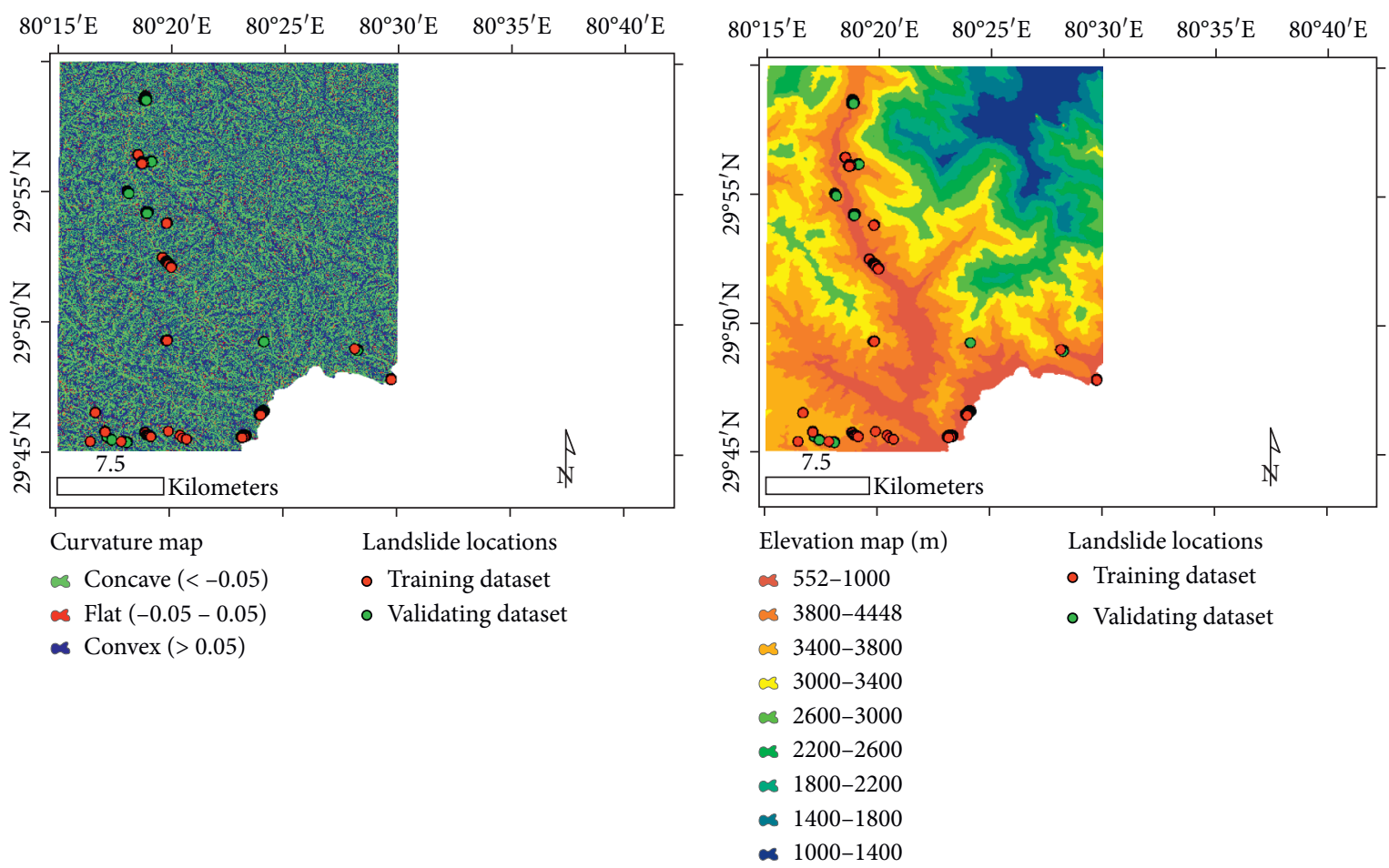

(c)

(d)

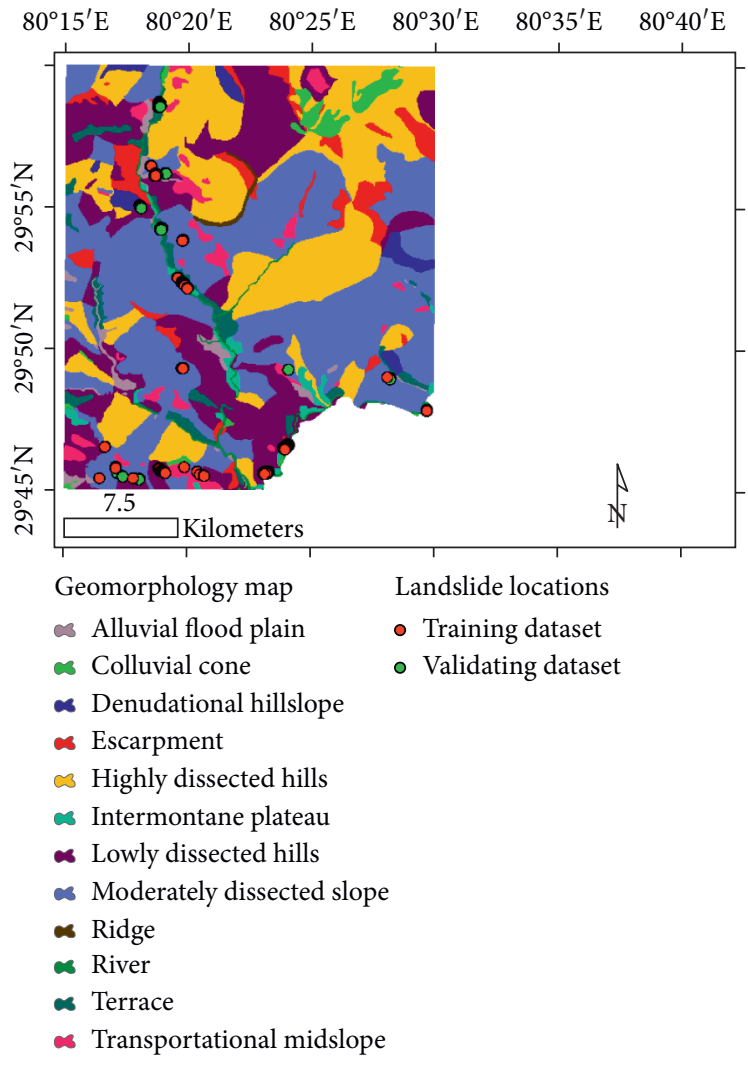

$80^{\circ} 15^{\prime} \mathrm{E} \quad 80^{\circ} 20^{\prime} \mathrm{E} \quad 80^{\circ} 25^{\prime} \mathrm{E} \quad 80^{\circ} 30^{\prime} \mathrm{E} \quad 80^{\circ} 35^{\prime} \mathrm{E} \quad 80^{\circ} 40^{\prime} \mathrm{E}$

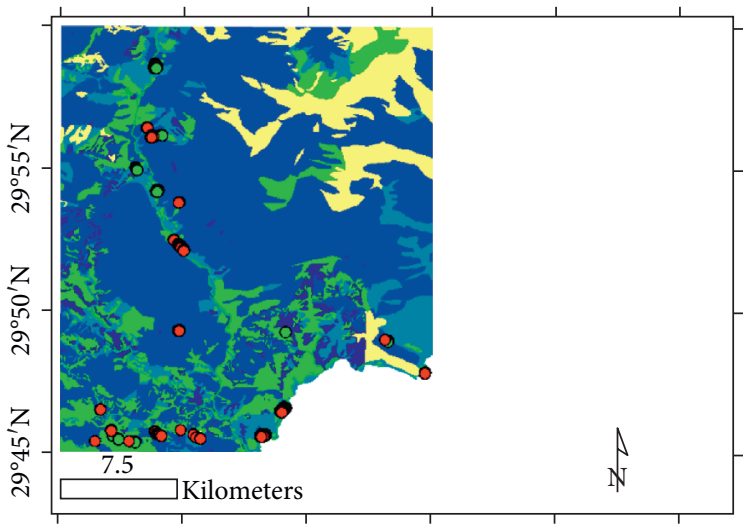

Land cover map Landslide locations

c) Barren rocky slope

$\approx$ Cultivated land

- Training dataset

* Moderately vegetated

- Validating dataset

* River

\& Settlement

* Sparsely vegetated

* Thickly vegetated

* Wasteland

(e)

FIgUre 3: Continued. 


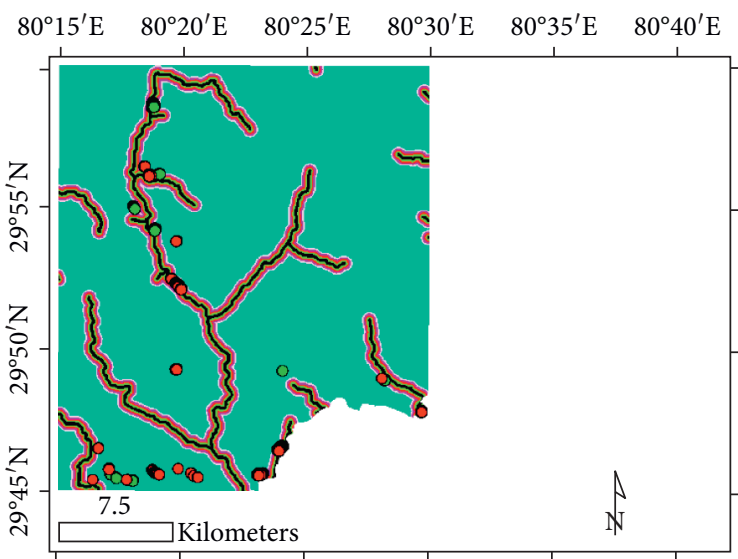

Distance to river map (m)

« 0-100

๑ 100-200

- 200-300

-300-400

¿3 400-500

$\sim 500$

(g)

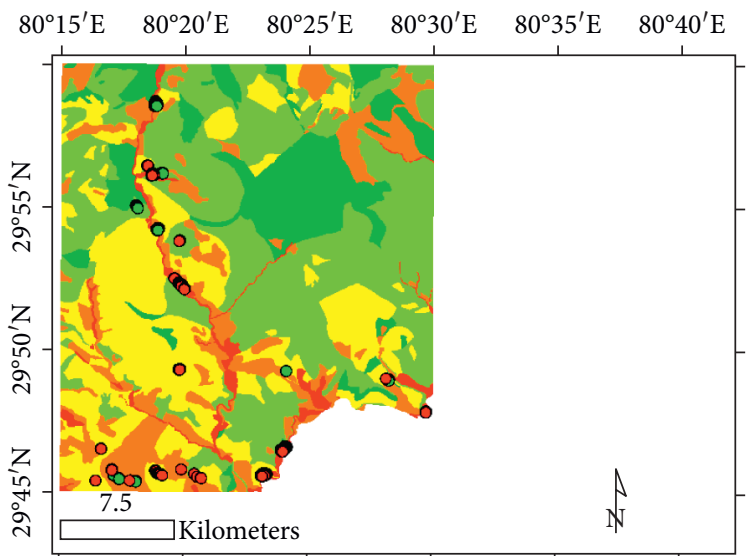

Overburden depth map

Landslide locations

$0 \mathrm{~m}$

๑ $0-1 \mathrm{~m}$

\& $1-2 \mathrm{~m}$

๑ $2-5 \mathrm{~m}$

* $>5 \mathrm{~m}$ $80^{\circ} 15^{\prime} \mathrm{E} \quad 80^{\circ} 20^{\prime} \mathrm{E} \quad 80^{\circ} 25^{\prime} \mathrm{E} \quad 80^{\circ} 30^{\prime} \mathrm{E} \quad 80^{\circ} 35^{\prime} \mathrm{E} \quad 80^{\circ} 40^{\prime} \mathrm{E}$

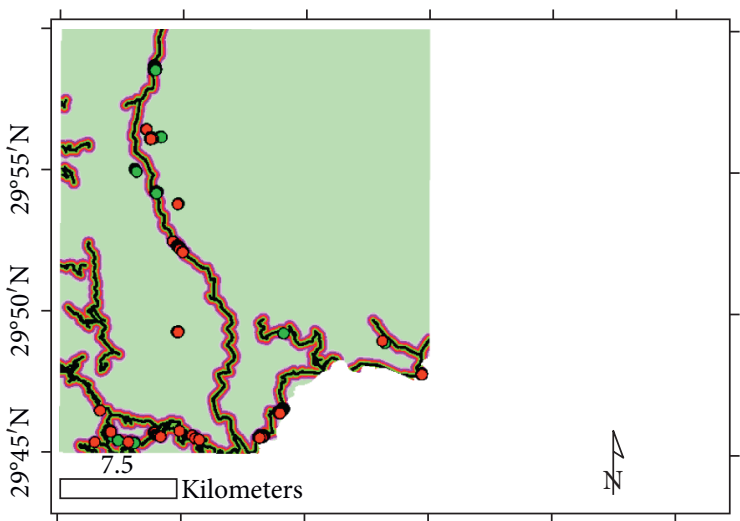

Distance to road map (m) Landslide locations
« $0-100$
- Training dataset

100-200

- Validating dataset

น 200-300

- 300-400

c) $400-500$

$\backsim>500$

(h)

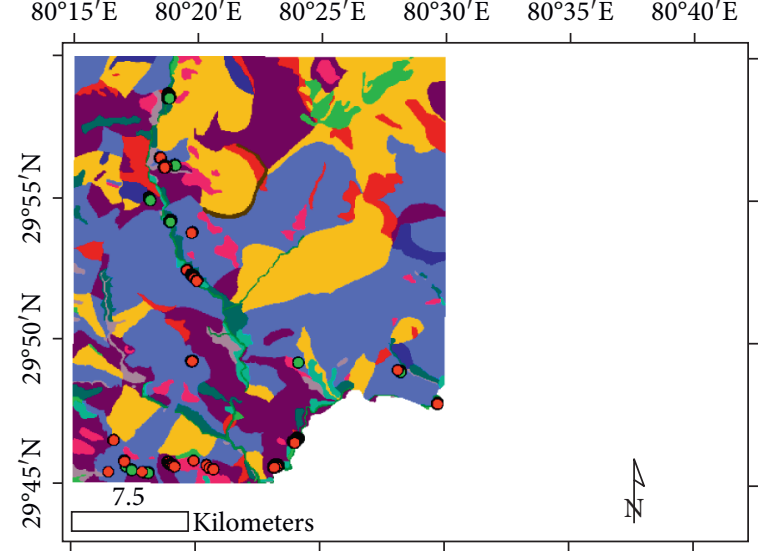

Geomorphology map

* Alluvial flood plain

Colluvial cone

* Denudational hillslope

* Escarpment

↔ Highly dissected hills

๘ Intermontane plateau

* Lowly dissected hills

* Moderately dissected slope

* Ridge

* River

* Terrace

* Transportational midslope
Landslide locations

- Training dataset

- Validating dataset

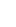


TABLE 1: Investigating the relationship between influencing factors and historical landslides events.

\begin{tabular}{|c|c|c|c|c|c|c|}
\hline Influencing factor & Class & Class pixels & Landslide pixels & $\%$ of class pixels & $\begin{array}{c}\% \text { of landslide } \\
\text { pixels }\end{array}$ & FR \\
\hline \multirow{5}{*}{ Slope $\left({ }^{\circ}\right)$} & $0-17.831476$ & 78092 & 34 & 11.48 & 8.44 & 0.73 \\
\hline & $17.831476-28.20698$ & 151464 & 64 & 22.28 & 15.88 & 0.71 \\
\hline & $28.20698-36.955399$ & 214040 & 110 & 31.48 & 27.30 & 0.87 \\
\hline & $36.955399-47.008942$ & 177197 & 146 & 26.06 & 36.23 & 1.39 \\
\hline & $47.008942-88.675705$ & 59172 & 49 & 8.70 & 12.16 & 1.40 \\
\hline \multirow{9}{*}{ Aspect } & Flat & 8 & 0 & 0.00 & 0.00 & 0.00 \\
\hline & North & 73688 & 2 & 10.84 & 0.50 & 0.05 \\
\hline & Northeast & 82949 & 9 & 12.20 & 2.23 & 0.18 \\
\hline & East & 77994 & 15 & 11.47 & 3.72 & 0.32 \\
\hline & Southeast & 91582 & 98 & 13.47 & 24.32 & 1.81 \\
\hline & South & 99895 & 93 & 14.69 & 23.08 & 1.57 \\
\hline & Southwest & 112712 & 104 & 16.58 & 25.81 & 1.56 \\
\hline & West & 77390 & 70 & 11.38 & 17.37 & 1.53 \\
\hline & Northwest & 63747 & 12 & 9.38 & 2.98 & 0.32 \\
\hline \multirow{3}{*}{ Curvature } & Concave $(<-0.05)$ & 327448 & 242 & 48.16 & 60.05 & 0.80 \\
\hline & Flat $(-0.05-0.05)$ & 24118 & 4 & 3.55 & 0.99 & 3.57 \\
\hline & Convex $(>0.05)$ & 328399 & 157 & 48.30 & 38.96 & 1.24 \\
\hline \multirow{9}{*}{ Elevation (m) } & $551-1000$ & 67334 & 217 & 9.90 & 53.85 & 5.46 \\
\hline & $1000-1400$ & 129487 & 163 & 19.04 & 40.45 & 2.13 \\
\hline & $1400-1800$ & 142551 & 23 & 20.96 & 5.71 & 0.27 \\
\hline & $1800-2200$ & 103742 & 0 & 15.26 & 0.00 & 0.00 \\
\hline & $2200-2600$ & 70883 & 0 & 10.42 & 0.00 & 0.00 \\
\hline & $2600-3000$ & 50912 & 0 & 7.49 & 0.00 & 0.00 \\
\hline & $3000-3400$ & 44923 & 0 & 6.61 & 0.00 & 0.00 \\
\hline & $3400-3800$ & 35722 & 0 & 5.25 & 0.00 & 0.00 \\
\hline & $3800-4448$ & 34411 & 0 & 5.06 & 0.00 & 0.00 \\
\hline \multirow{12}{*}{ Geomorphology } & Alluvial flood plain & 10738 & 20 & 1.58 & 4.96 & 3.14 \\
\hline & Colluvial cone & 12372 & 20 & 1.82 & 4.96 & 2.73 \\
\hline & Denudational hillslope & 11320 & 0 & 1.66 & 0.00 & 0.00 \\
\hline & Escarpment & 33142 & 32 & 4.87 & 7.94 & 1.63 \\
\hline & Highly dissected hills & 169413 & 0 & 24.91 & 0.00 & 0.00 \\
\hline & Intermontane plateau & 8901 & 47 & 1.31 & 11.66 & 8.91 \\
\hline & Lowly dissected hills & 125714 & 134 & 18.49 & 33.25 & 1.80 \\
\hline & Moderately dissected slope & 257637 & 57 & 37.89 & 14.14 & 0.37 \\
\hline & Ridge & 2262 & 0 & 0.33 & 0.00 & 0.00 \\
\hline & River & 7634 & 0 & 1.12 & 0.00 & 0.00 \\
\hline & Terrace & 20227 & 85 & 2.97 & 21.09 & 7.09 \\
\hline & Transportational mid slope & 20605 & 8 & 3.03 & 1.99 & 0.66 \\
\hline \multirow{18}{*}{ Lithology } & Group 1 & 10524 & 13 & 1.55 & 3.23 & 2.09 \\
\hline & Group 2 & 4889 & 0 & 0.72 & 0.00 & 0.00 \\
\hline & Group 3 & 2229 & 0 & 0.33 & 0.00 & 0.00 \\
\hline & Group 4 & 934 & 0 & 0.14 & 0.00 & 0.00 \\
\hline & Group 5 & 46595 & 1 & 6.85 & 0.25 & 0.04 \\
\hline & Group 6 & 431 & 0 & 0.06 & 0.00 & 0.00 \\
\hline & Group 7 & 56013 & 79 & 8.24 & 19.60 & 2.39 \\
\hline & Group 8 & 18060 & 0 & 2.66 & 0.00 & 0.00 \\
\hline & Group 9 & 145233 & 18 & 21.36 & 4.47 & 0.21 \\
\hline & Group 10 & 4563 & 0 & 0.67 & 0.00 & 0.00 \\
\hline & Group 11 & 12901 & 0 & 1.90 & 0.00 & 0.00 \\
\hline & Group 12 & 239 & 0 & 0.04 & 0.00 & 0.00 \\
\hline & Group 13 & 222105 & 165 & 32.66 & 40.94 & 1.26 \\
\hline & Group 14 & 23382 & 0 & 3.44 & 0.00 & 0.00 \\
\hline & Group 15 & 15561 & 63 & 2.29 & 15.63 & 6.86 \\
\hline & Group 16 & 100193 & 1 & 14.74 & 0.25 & 0.02 \\
\hline & Group 17 & 10168 & 63 & 1.50 & 15.63 & 10.50 \\
\hline & Group 18 & 5945 & 0 & 0.87 & 0.00 & 0.00 \\
\hline
\end{tabular}


TABLE 1: Continued.

\begin{tabular}{|c|c|c|c|c|c|c|}
\hline Influencing factor & Class & Class pixels & Landslide pixels & $\%$ of class pixels & $\begin{array}{c}\% \text { of landslide } \\
\text { pixels }\end{array}$ & FR \\
\hline \multirow{8}{*}{ Land cover } & Barren rocky slope & 64898 & 0 & 9.54 & 0.00 & 0.00 \\
\hline & Cultivated land & 230 & 0 & 0.03 & 0.00 & 0.00 \\
\hline & Moderately vegetated & 101713 & 19 & 14.96 & 4.71 & 0.32 \\
\hline & River & 6703 & 0 & 0.99 & 0.00 & 0.00 \\
\hline & Settlement & 1262 & 0 & 0.19 & 0.00 & 0.00 \\
\hline & Sparsely vegetated & 79783 & 253 & 11.73 & 62.78 & 5.35 \\
\hline & Thickly vegetated & 392670 & 63 & 57.75 & 15.63 & 0.27 \\
\hline & Wasteland & 32706 & 68 & 4.81 & 16.87 & 3.51 \\
\hline \multirow{6}{*}{ Distance to roads $(\mathrm{m})$} & $0-100$ & 30626 & 228 & 4.50 & 56.58 & 12.62 \\
\hline & $100-200$ & 26040 & 88 & 3.83 & 21.84 & 5.73 \\
\hline & $200-300$ & 23462 & 11 & 3.45 & 2.73 & 0.79 \\
\hline & $300-400$ & 21727 & 5 & 3.20 & 1.24 & 0.39 \\
\hline & $400-500$ & 20576 & 0 & 3.03 & 0.00 & 0.00 \\
\hline & $>500$ & 557534 & 71 & 81.99 & 17.62 & 0.22 \\
\hline \multirow{6}{*}{ Distance to rivers $(\mathrm{m})$} & $0-100$ & 25667 & 124 & 3.77 & 30.77 & 8.19 \\
\hline & $100-200$ & 25331 & 79 & 3.73 & 19.60 & 5.29 \\
\hline & $200-300$ & 25346 & 22 & 3.73 & 5.46 & 1.47 \\
\hline & $300-400$ & 25247 & 25 & 3.71 & 6.20 & 1.68 \\
\hline & $400-500$ & 25111 & 10 & 3.69 & 2.48 & 0.67 \\
\hline & $>500$ & 553263 & 143 & 81.37 & 35.48 & 0.44 \\
\hline \multirow{5}{*}{ Valley depth (m) } & $0 \mathrm{~m}$ & 94613 & 28 & 13.91 & 6.95 & 0.50 \\
\hline & $0-1 \mathrm{~m}$ & 271934 & 77 & 39.99 & 19.11 & 0.48 \\
\hline & $1-2 \mathrm{~m}$ & 186081 & 101 & 27.37 & 25.06 & 0.92 \\
\hline & $2-5 \mathrm{~m}$ & 106521 & 97 & 15.67 & 24.07 & 1.54 \\
\hline & $>5 \mathrm{~m}$ & 20816 & 100 & 3.06 & 24.81 & 8.14 \\
\hline
\end{tabular}

4.2.9. Lithology. Lithology is important in identifying the type of rocks/soil vulnerable to cause landslides in the events of rainfall and gravitational forces acting on the ground [84-86]. The map of the lithology of the study area was obtained from the website of Geological Survey of India (https://earthexplorer.usgs.gov) and classified into 18 main groups as follows: group 1 (alluvium and colluvium); group 2 (alluvium, in situ soil); group 3 (amphibolite and mica schist); group 4 (phyllite, quartzite, slate, and limestone); group 5 (carbonaceous phyllite, quartzite, slate, and limestone); group 6 (chlorite schist and massive amphibolite); group 7 (colluvium); group 8 (glacial deposit); group 9 (gravel, boulder embedded in oxidised sandy matrix); group 10 (granite with tourmaline and quartz vein); group 11 (morainic material); group 12 (quartz, mica, chlorite, and hornblende schist); group 13 (scree); group 14 (slate, quartzite, sandstone, talc, lLimestone, dolomite, and stromatolitic limestone); group 15 (stromatolitic dolomitic limestone, phyllite, and talc); group 16 (transported soil and scree); group 17 (alluvium); and group 18 (younger loose debris). The results of the FR method revealed that the areas where group $17(\mathrm{FR}=10.50)$, group $7(\mathrm{FR}=2.39)$, group 1 $(\mathrm{FR}=2.09)$, and group $13(\mathrm{FR}=1.26)$ were the most susceptible portions of the study area to landslide occurrence.

4.2.10. Overburden Depth. The overburden depth represents the information on the soil/overburden thickness that is controlled by erosion processes and slope morphometry $[87,88]$ and can affect shallow translational debris landslides [89]. Overburden maps are important for identifying slump and creep types of probable landslide areas. In this study, the map of overburden depth was extracted from the website of Geological Survey of India (https://earthexplorer.usgs.gov) and classified into five classes (Figure 3 and Table 1). Most of the landslides occurred when the depth of the overburden was greater than $5 \mathrm{~m}$. The FR value in this class in the present case is 8.14 , which is on the river valleys slopes.

\section{Methodology}

Our methodology is presented in Figure 4 and briefly described as follows:

(1) Generation of a database of past landslides using satellite and Google Earth images in conjunction with extracted data from the GSI report

(2) Random split of landslide points (polygons represented by points) into two groups: $70 \%$ for the training and $30 \%$ for the validation of the models

(3) Development of thematic maps of landslide influencing factors such as slope, aspect, curvature, elevation, land cover, lithology, geomorphology, distance to rivers, distance to roads, and overburden depth, as well as synthesis of available data from various sources

(4) Spatial modeling and generation of landslide susceptibility maps of the study area using the LDA, LR, and RBFN models

(5) Performance evaluation of the models using ACC, SPF, SST, PPV, NPV, Kappa, RMSE, and ROC-AUC metrics 


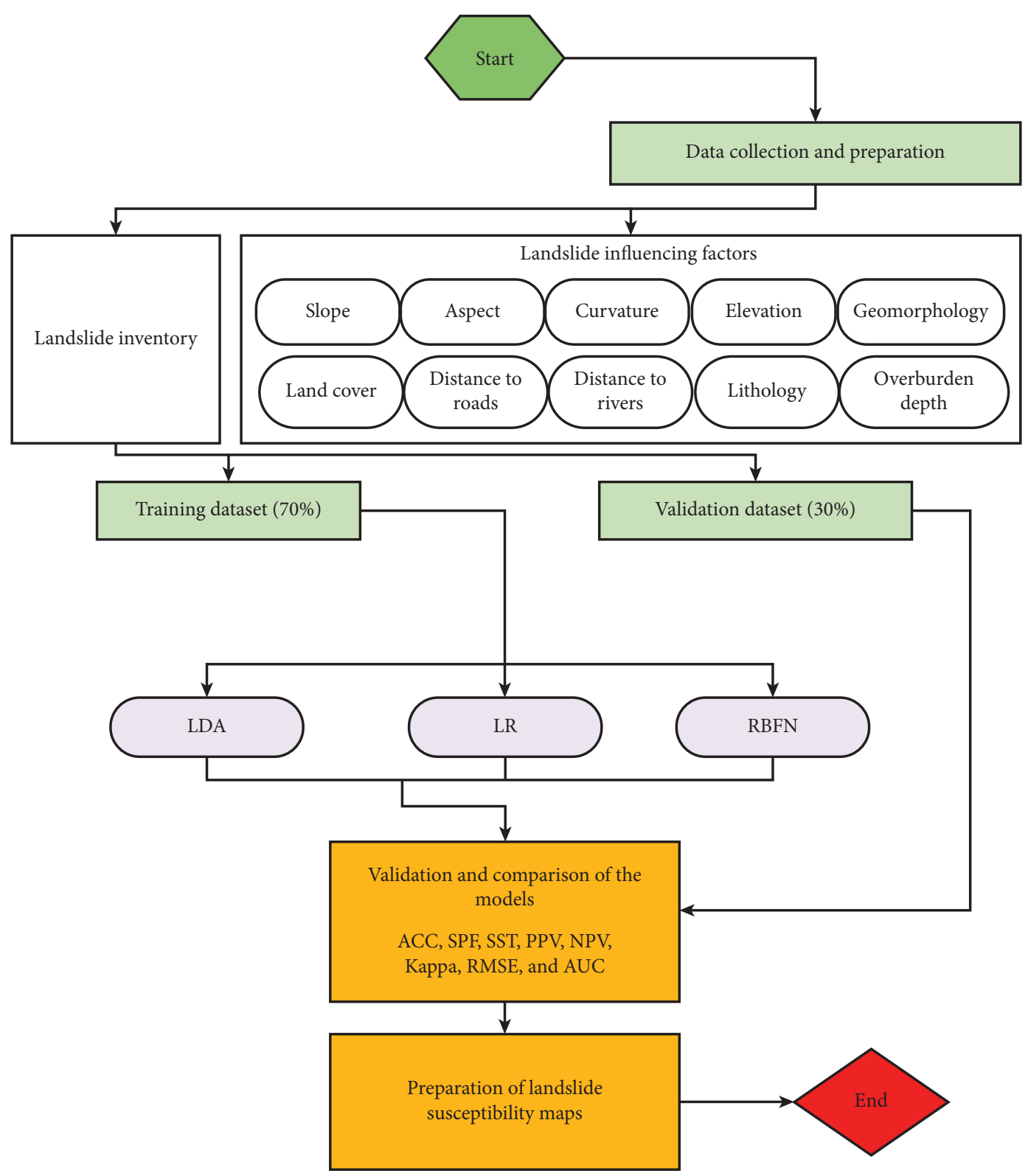

FIGURE 4: Methodological framework for landslide susceptibility mapping using the LDA, LR, and RBFN models.

\section{Results}

6.1. Validation of the Models. The evaluation results of the LDA, LR, and RBFN ML models are presented in Table 2. In the training phase, $L R$ is the most accurate in terms of the NPV rating index (85.82). Other statistical measures indicated that performance of the RBFN algorithm is the best $(\mathrm{PPV}=86.97 \%, \mathrm{SST}=85.66 \%, \mathrm{SPF}=86.77 \%$, $\mathrm{ACC}=86.21 \%$, and kappa $=0.72$ ). In the validation phase, LDA shows the best performance in terms of the NPV (81.75) and SST (82.01) metrics. In addition, LR outperforms the other models in terms of the PPV (87.59), SPF (86.29), ACC (82.85), and kappa (0.66) metrics. RBFN shows a validation performance similar to LR in terms of the ACC (82.85) and kappa (0.66) metrics.
TABle 2: Performance analysis of the models.

\begin{tabular}{lcccccc}
\hline \multirow{2}{*}{ Parameters } & \multicolumn{3}{c}{ Training } & \multicolumn{3}{c}{ Validation } \\
& LDA & LR & RBFN & LDA & LR & RBFN \\
\hline PPV (\%) & 85.06 & 84.29 & 86.97 & 83.21 & 87.59 & 86.86 \\
NPV (\%) & 82.76 & 85.82 & 85.44 & 81.75 & 78.10 & 78.83 \\
SST (\%) & 83.15 & 85.60 & 85.66 & 82.01 & 80.00 & 80.41 \\
SPF (\%) & 84.71 & 84.53 & 86.77 & 82.96 & 86.29 & 85.71 \\
ACC (\%) & 83.91 & 85.06 & 86.21 & 82.48 & 82.85 & 82.85 \\
Kappa & 0.68 & 0.70 & 0.72 & 0.65 & 0.66 & 0.66 \\
\hline
\end{tabular}

In terms of RMSE, the LR (0.319) and RBFN (0.319) models have better results than LDA (0.337) in the training phase (Figure 5). In the validation phase, the RBFN model with RMSE $=0.327$ has the lowest modeling error compared to the LR (0.337) and LDA (0.344) models (Figure 6). 


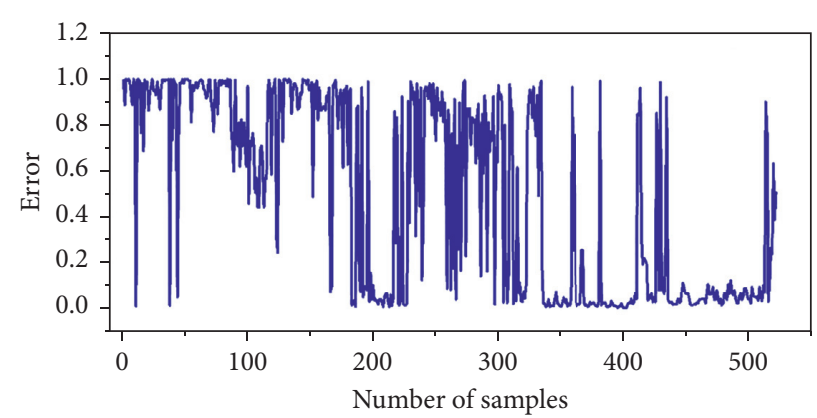

LDA $($ RMSE $=0.337)$

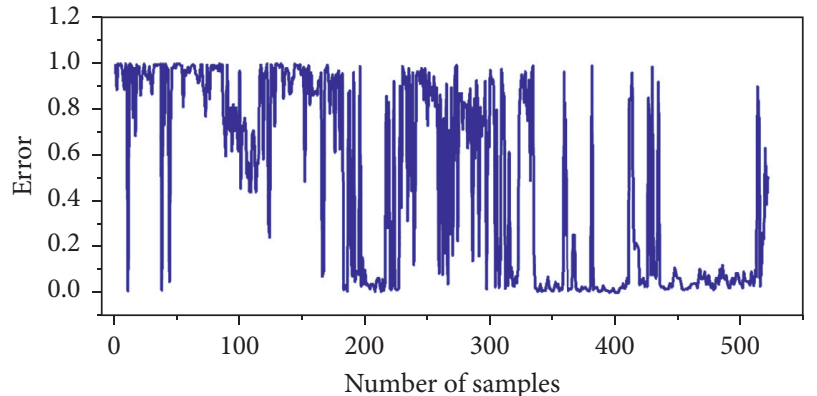

LDA $($ RMSE $=0.337)$

(a)

(b)

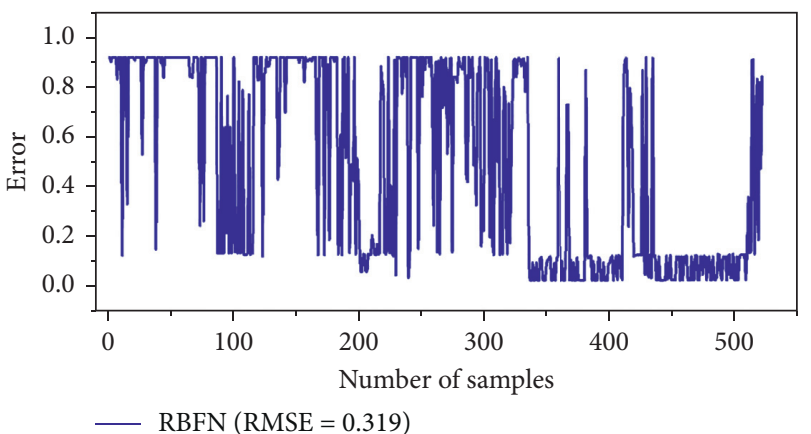

(c)

FIGURE 5: RMSE of the models in the training phase.

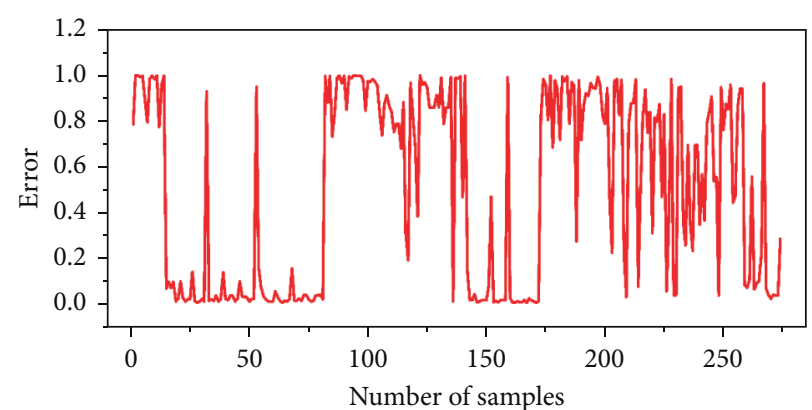

$-\operatorname{LDA}($ RMSE $=0.344)$

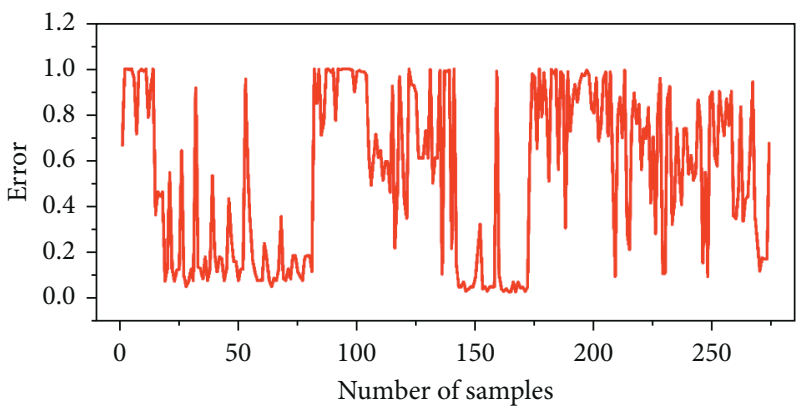

$\longrightarrow$ LR $($ RMSE $=0.337)$

(a)

(b)

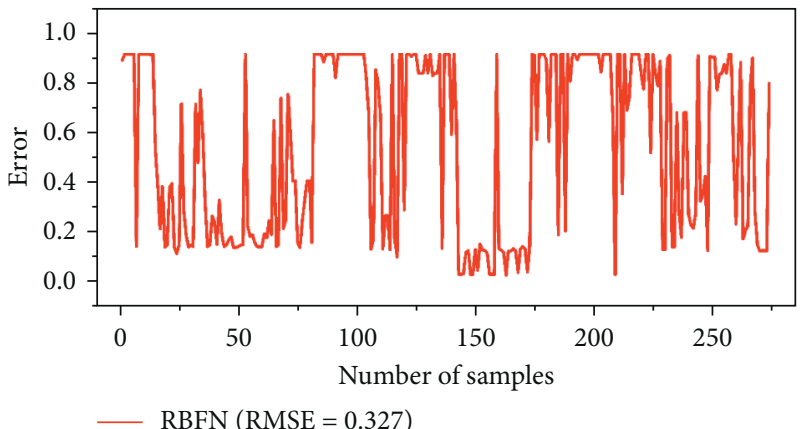

(c)

FIgURE 6: RMSE of the models in the validation phase. 


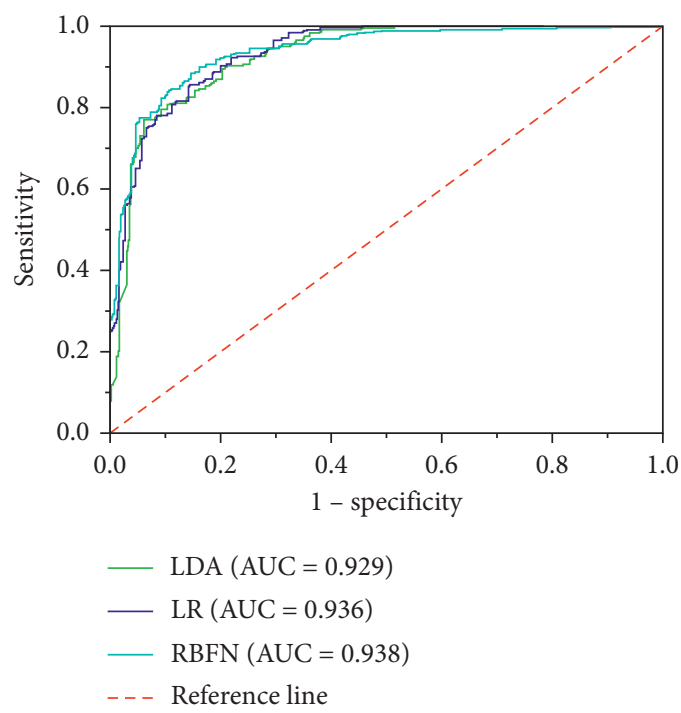

(a)

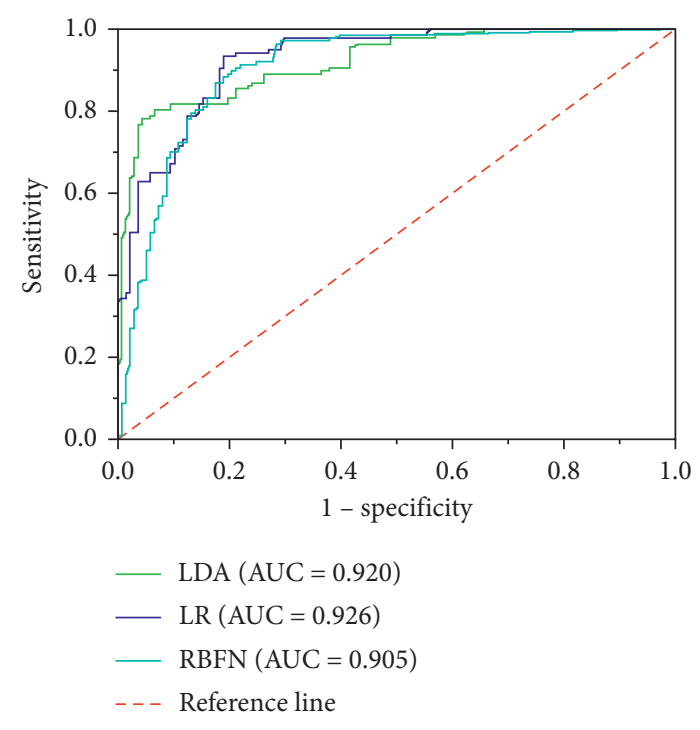

(b)

Figure 7: AUC values of the models using the training (a) and validation (b) datasets.

The AUC value for the training phase is the highest for the RBFN model (0.938) in comparison with the LDA (0.929) and LR (0.936) models. However, in the validation phase, the RBFN model has a lower AUC (0.805) compared to the $\mathrm{LR}(\mathrm{AUC}=0.926)$ and $\mathrm{LDA}(\mathrm{AUC}=0.920)$ (Figure 7$)$. According to the results, the LR model is the most accurate model for the prediction of landslide susceptibility in the study area.

6.2. Construction of Landslide Susceptibility Maps. Landslide susceptibility maps were produced using the models' outputs that gave landslide susceptibility values ranging from 0 to 1 . These raster values maps were classified into five susceptibility classes using the natural break method of ArcGIS (Figure 8).

Figure 9 shows FR analysis of the susceptibility maps. On the FR diagram, it is clear that the landslides are mostly located in the very high susceptibility class. Further, with a closer look, it can be seen that the LR model has the highest frequency of landslides in the very high susceptibility class, followed by the LDA and RBFN models. On the other hand, a few landslides fall into the very low susceptibility class. In the very low landslide susceptibility class, RBFN showed the highest percentage of susceptibility, followed by LDA and LR, respectively.

\section{Discussion}

Nowadays, ML methods are used for the development of landslide susceptibility maps in many regions around the world [90]. In the ML modeling, binary classification is adopted, where " 0 " indicates presence and " 1 " indicates absence of landslides. The ML models used in the landslide studies are based on single, ensemble, and hybrid algorithms. In this study, we have used three single ML models, namely, LDA, LR, and RBFN, for the generation of landslide susceptibility maps of Pithoragarh district, which is one of the landslide-prone areas in Northern India. These models have been selected as they have not been earlier applied for the landslide susceptibility mapping of this part of the Himalayas. Ten landslide influencing factors (slope, aspect, curvature, elevation, land cover, lithology, geomorphology, distance to rivers, distance to roads, and overburden depth) were used for the landslide susceptibility mapping. Drainage in the area is structurally controlled by faults/ lineaments, so this factor has not been considered separately in the model study to avoid duplication. Moreover, rainfall has been considered as a triggering factor, not as an influencing factor, because most of the landslides in this area occurred during the rainy season. For the model development and validation, landslide data was split into a $70 / 30$ ratio: $70 \%$ for training and $30 \%$ for testing validation based on the experience of researchers [91, 92].

Performance of the models was checked using standard statistical metrics: ACC, PPV, NPV, SPF, SST, Kappa, RMSE, and AUC, which have also been used by several researchers $[46,93,94]$. All the three models used in this study have shown good performance in predicting landslide susceptible zones with high accuracy which is consistent with other similar studies in other areas $[48,95]$. However, the LR model with the AUC value of 0.926 is the most accurate and consequently the best model in predicting the landslide susceptibility in this area. The results revealed that about $20 \%$ of the study area fell in the high and very high susceptibility classes. The 


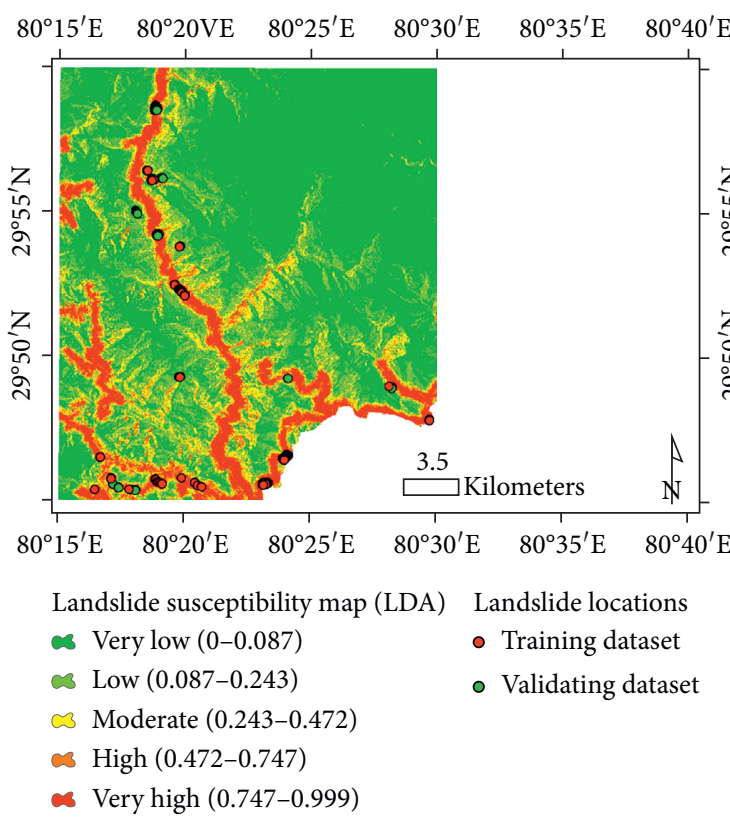

(a)

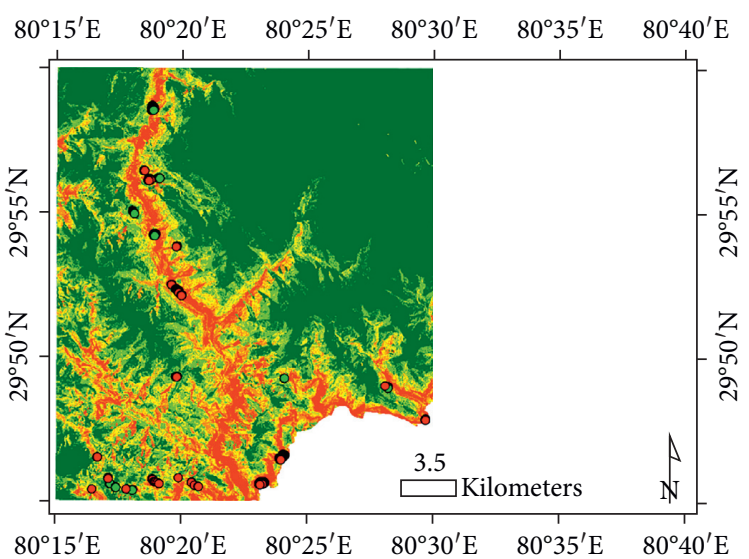

Landslide susceptibility map (LR)

Landslide locations

- Training dataset

- Validating dataset

\& Low $(0.097-0.269)$

cs Moderate (0.269-0.479)

High $(0.479-0.718)$

* Very high (0.718-0.996)

(b)

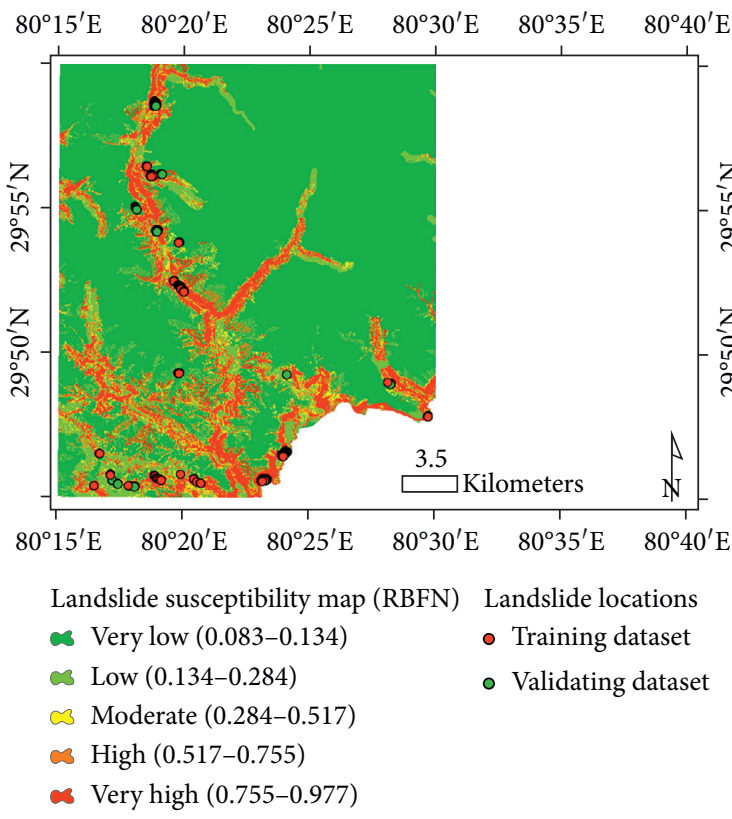

(c)

FIgURE 8: Landslide susceptibility maps generated using the LDA (a), LR (b), and RBFN (c) models.

first two classes (0-100 and 100-200 m) of distance to roads and rivers had the strongest association with the historical landslides in the study. This association was perfectly reflected in the susceptibility maps such that the areas at a distance to roads/rivers of $0-200 \mathrm{~m}$ were classified as high and very high susceptibility classes to landslide occurrence. Our results are supported by previous studies that had reported on the significance of roads and rivers on landslide occurrence [78, 96-98]. Delineation of accurate landslide susceptible zones using single models will help in better planning and management of the study area. Overall, this case study demonstrated that the single models can still compete with the complex ensemble and hybrid models for landslide susceptibility mapping of landslide-prone areas. 


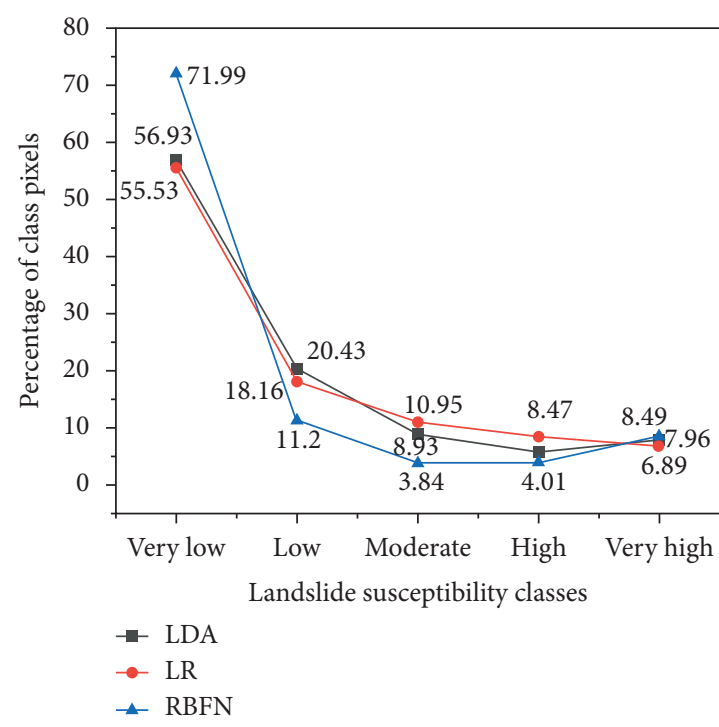

(a)

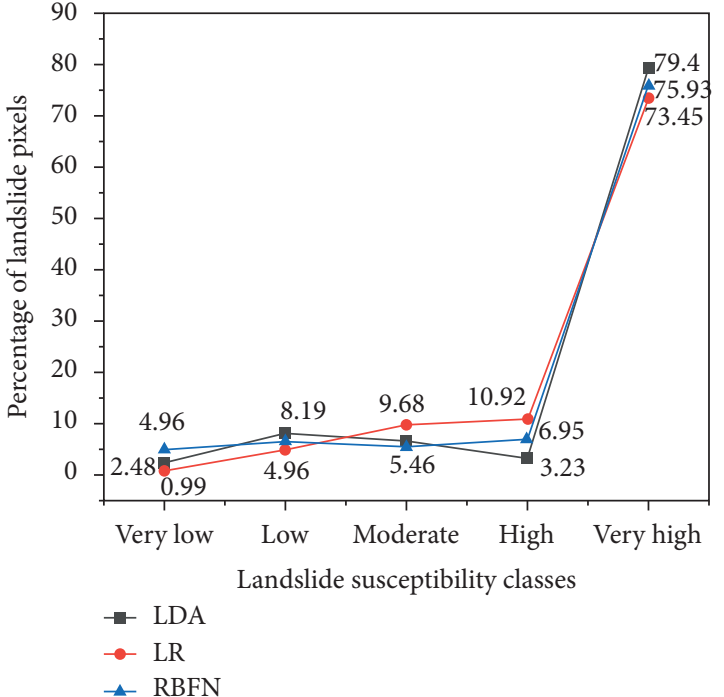

(b)

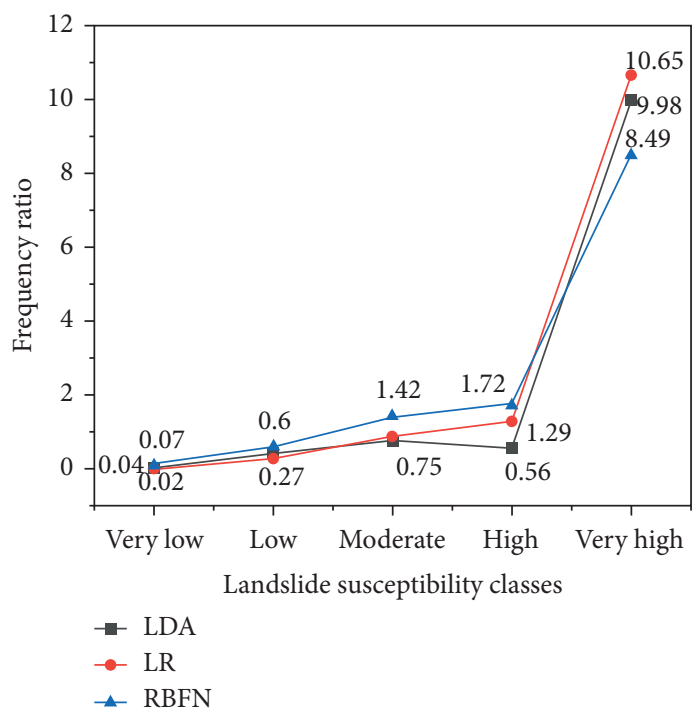

(c)

FIgURe 9: Analysis of the landslide density on the susceptibility maps.

\section{Concluding Remarks}

Using three single ML models, we have modeled landslide susceptibility in one of the landslide-prone areas of the Himalayas. Results indicated that the LR model was the best model with an AUC value of 0.926 , which can be considered an excellent model for predicting the landslide susceptibility of hilly and mountainous areas. Despite widespread development and application of ensemble and hybrid models, our results suggest that single ML models are still efficient in producing accurate landslide susceptibility maps for better planning and management of landslide-prone areas. However, the applicability of these models for other areas depends on local conditions that may change the set of landslide influencing factors. This uncertainty should be addressed by repeating such a study in different landslide-prone regions around the world.

\section{Data Availability}

The data used to support the findings of this study are available from the corresponding author upon request.

\section{Conflicts of Interest}

The authors declare that there are no conflicts of interest.

\section{Acknowledgments}

The authors acknowledge University of Transport Technology for supporting this research. 


\section{References}

[1] D. H. Radbruch-Hall and D. J. Varnes, "Landslides-cause and effect," Bulletin of the International Association of Engineering Geology, vol. 13, no. 1, pp. 205-216, 1976.

[2] M. R. Setayeshirad, M. R. Nikudel, and A. Uromeihy, "Landslide susceptibility assessment along the southern coast of the Caspian sea, Iran," Natural Hazards, vol. 69, no. 3, pp. 2215-2232, 2013.

[3] A. Akgun, "A comparison of landslide susceptibility maps produced by logistic regression, multi-criteria decision, and likelihood ratio methods: a case study at İmir, Turkey," Landslides, vol. 9, no. 1, pp. 93-106, 2012.

[4] A. Dikshit, N. Satyam, B. Pradhan, and S. Kushal, "Estimating rainfall threshold and temporal probability for landslide occurrences in Darjeeling Himalayas," Geosciences Journal, vol. 24, no. 2, pp. 225-233, 2020.

[5] D. Mafi-Gholami, A. Jaafari, E. K. Zenner, A. Tien Bui, and D. T. Bui, "Vulnerability of coastal communities to climate change: thirty-year trend analysis and prospective prediction for the coastal regions of the Persian gulf and gulf of Oman," The Science of the Total Environment, vol. 741, Article ID 140305, 2020

[6] I. Das, A. Stein, N. Kerle, and V. K. Dadhwal, "Landslide susceptibility mapping along road corridors in the Indian Himalayas using Bayesian logistic regression models," Geomorphology, vol. 179, pp. 116-125, 2012.

[7] Y. Wang, H. Duan, and H. Hong, "A comparative study of composite kernels for landslide susceptibility mapping: a case study in Yongxin County, China," Catena, vol. 183, Article ID 104217, 2019.

[8] P. Tsangaratos and I. Ilia, "Comparison of a logistic regression and Naïve Bayes classifier in landslide susceptibility assessments: the influence of models complexity and training dataset size," Catena, vol. 145, pp. 164-179, 2016.

[9] F. Huang, J. Zhang, C. Zhou, Y. Wang, J. Huang, and L. Zhu, "A deep learning algorithm using a fully connected sparse autoencoder neural network for landslide susceptibility prediction," Landslides, vol. 17, no. 1, pp. 217-229, 2020.

[10] B. T. Pham, "A novel classifier based on composite hypercubes on iterated random projections for assessment of landslide susceptibility," Journal of the Geological Society of India, vol. 91, no. 3, pp. 355-362, 2018.

[11] X. Zhao and W. Chen, "GIS-based evaluation of landslide susceptibility models using certainty factors and functional trees-based ensemble techniques," Applied Sciences, vol. 10, no. 1, p. 16, 2020.

[12] Q. C. Tran, D. D. Minh, A. Jaafari et al., "Novel ensemble landslide predictive models based on the hyperpipes algorithm: a case study in the nam dam commune, vietnam," Applied Sciences, vol. 10, no. 11, 2020.

[13] A. Jaafari, M. Panahi, B. T. Pham et al., "Meta optimization of an adaptive neuro-fuzzy inference system with grey wolf optimizer and biogeography-based optimization algorithms for spatial prediction of landslide susceptibility," Catena, vol. 175, pp. 430-445, 2019.

[14] B. T. Pham, A. Jaafari, T. Nguyen-Thoi et al., "Ensemble machine learning models based on reduced error pruning tree for prediction of rainfall-induced landslides," International Journal of Digital Earth, vol. 14, pp. 1-22, 2020.

[15] M. Abedini and C. Zhang, "Dynamic vulnerability assessment and damage prediction of RC columns subjected to severe impulsive loading," Structural Engineering \& Mechanics, vol. 77, no. 4, pp. 441-461, 2021.
[16] C. Zhang, Z. Alam, L. Sun, Z. Su, and B. Samali, "Fibre Bragg grating sensor-based damage response monitoring of an asymmetric reinforced concrete shear wall structure subjected to progressive seismic loads," Structural Control and Health Monitoring, vol. 26, no. 3, p. e2307, 2019.

[17] Z. Liu, G. Gilbert, J. M. Cepeda et al., "Modelling of shallow landslides with machine learning algorithms," Geoscience Frontiers, vol. 12, no. 1, pp. 385-393, 2021.

[18] M. Marjanović, M. Kovačević, B. Bajat, and V. J. E. G. Voženílek, "Landslide susceptibility assessment using SVM machine learning algorithm," Engineering Geology, vol. 123, no. 3, pp. 225-234, 2011.

[19] Q. He, H. Shahabi, A. Shirzadi et al., "Landslide spatial modelling using novel bivariate statistical based Naïve Bayes, RBF Classifier, and RBF network machine learning algorithms," The Science of the Total Environment, vol. 663, pp. 1-15, 2019.

[20] Y.-R. Guo, Y.-Q. Bai, C.-N. Li, Y.-H. Shao, Y.-F. Ye, and C.-z. Jiang, "Reverse nearest neighbors Bhattacharyya bound linear discriminant analysis for multimodal classification," Engineering Applications of Artificial Intelligence, vol. 97, Article ID 104033, 2021.

[21] L. C. Djoufack Nkengfack, D. Tchiotsop, R. Atangana, V. Louis-Door, and D. Wolf, "EEG signals analysis for epileptic seizures detection using polynomial transforms, linear discriminant analysis and support vector machines," Biomedical Signal Processing and Control, vol. 62, Article ID 102141, 2020.

[22] A. Subasi and M. Ismail Gursoy, "EEG signal classification using PCA, ICA, LDA and support vector machines," Expert Systems with Applications, vol. 37, no. 12, pp. 8659-8666, 2010.

[23] F. Jiang, Z. Guan, Z. Li, and X. Wang, "A method of predicting visual detectability of low-velocity impact damage in composite structures based on logistic regression model," Chinese Journal of Aeronautics, vol. 34, 2020.

[24] L. Chao, K. Zhang, Z. Li, Y. Zhu, J. Wang, and Z. Yu, "Geographically weighted regression based methods for merging satellite and gauge precipitation," Journal of $\mathrm{Hy}$ drology, vol. 558, pp. 275-289, 2018.

[25] Y. Fan, J. Bai, X. Lei et al., "Privacy preserving based logistic regression on big data," Journal of Network and Computer Applications, vol. 171, Article ID 102769, 2020.

[26] C.-Y. J. Peng, K. L. Lee, and G. M. Ingersoll, “An introduction to logistic regression analysis and reporting," The Journal of Educational Research, vol. 96, no. 1, pp. 3-14, 2002.

[27] M. Shi, B. Wang, Y. Shen et al., "3D assembly of MXenestabilized spinel $\mathrm{ZnMn} 2 \mathrm{O} 4$ for highly durable aqueous zincion batteries," Chemical Engineering Journal, vol. 399, Article ID 125627, 2020.

[28] L. Bottou, "Large-Scale machine learning with stochastic gradient descent," in Proceedings of COMPSTAT, Y. Lechevallier and G. Saporta, Eds., Physica-Verlag HD, Heidelberg, Germany, 2010.

[29] P. Strumiłło and W. Kamiński, "Radial basis function neural networks: theory and applications," in Neural Networks and Soft Computing, L. Rutkowski and J. Kacprzyk, Eds., PhysicaVerlag HD, Heidelberg, Germany, 2003.

[30] F. Chen, Z. Jin, E. Wang et al., "Relationship model between surface strain of concrete and expansion force of reinforcement rust," Scientific Reports, vol. 11, no. 1, pp. 1-11, 2021.

[31] F.-x. Chen, Y.-c. Zhong, X.-y. Gao et al., "Non-uniform model of relationship between surface strain and rust expansion 
force of reinforced concrete," Scientific Reports, vol. 11, no. 1, pp. 1-9, 2021.

[32] B. Fornberg, E. Larsson, and N. Flyer, "Stable computations with Gaussian radial basis functions," SIAM Journal on Scientific Computing, vol. 33, no. 2, pp. 869-892, 2011.

[33] Y. Bai, S. Wang, B. Mou, Y. Wang, and K. A. Skalomenos, "Bidirectional seismic behavior of steel beam-column connections with outer annular stiffener," Engineering Structures, vol. 227, Article ID 111443, 2021.

[34] A. K. Jain, "Data clustering: 50 years beyond K-means," Pattern Recognition Letters, vol. 31, no. 8, pp. 651-666, 2010.

[35] H. Sheng, S. Wang, Y. Zhang et al., "Near-online tracking with Co-occurrence constraints in blockchain-based edge computing," IEEE Internet of Things Journal, vol. 8, 2020.

[36] C. M. Bishop, Neural Networks for Pattern Recognition, Oxford University Press, Oxford, UK, 1995.

[37] Q. Dong and L. Cui, "Reliability analysis of a system with twostage degradation using Wiener processes with piecewise linear drift," IMA Journal of Management Mathematics, vol. 32, no. 1, pp. 3-29, 2021.

[38] P. Hu, L. Cao, J. Su, Q. Li, and Y. Li, "Distribution characteristics of salt-out particles in steam turbine stage," Energy, vol. 192, Article ID 116626, 2020.

[39] Q. Jiang, F. Shao, W. Lin, K. Gu, G. Jiang, and H. Sun, "Optimizing multistage discriminative dictionaries for blind image quality assessment," IEEE Transactions on Multimedia, vol. 20, no. 8, pp. 2035-2048, 2017.

[40] A. Jaafari, E. K. Zenner, and B. T. Pham, "Wildfire spatial pattern analysis in the Zagros mountains, Iran: a comparative study of decision tree based classifiers," Ecological Informatics, vol. 43, pp. 200-211, 2018.

[41] P. T. Nguyen, D. H. Ha, A. Jaafari et al., "Groundwater potential mapping combining artificial neural network and real AdaBoost ensemble technique: the DakNong province case-study, Vietnam," International Journal of Environmental Research and Public Health, vol. 17, no. 7, p. 2473, 2020.

[42] B. T. Pham, A. Jaafari, M. Avand et al., "Performance evaluation of machine learning methods for forest fire modeling and prediction," Symmetry, vol. 12, no. 6, p. 1022, 2020.

[43] V.-H. Nhu, A. Mohammadi, H. Shahabi et al., "Landslide susceptibility mapping using machine learning algorithms and remote sensing data in a tropical environment," International Journal of Environmental Research and Public Health, vol. 17, no. 14, p. 4933, 2020.

[44] B. T. Pham, A. Jaafari, T. V. Phong et al., "Improved flood susceptibility mapping using a best first decision tree integrated with ensemble learning techniques," Geoscience Frontiers, vol. 12, no. 3, Article ID 101105, 2021.

[45] T. T. Tuyen, A. Jaafari, H. P. H. Yen et al., "Mapping forest fire susceptibility using spatially explicit ensemble models based on the locally weighted learning algorithm," Ecological Informatics, vol. 63, Article ID 101292, 2021.

[46] L. Shano, T. K. Raghuvanshi, and M. Meten, "Landslide susceptibility evaluation and hazard zonation techniques - a review," Geoenvironmental Disasters, vol. 7, no. 1, 2020.

[47] T. V. Phong, T. T. Phan, I. Prakash et al., "Landslide susceptibility modeling using different artificial intelligence methods: a case study at Muong Lay district, Vietnam," Geocarto International, pp. 1-24, 2019.

[48] B. Feby, A. L. Achu, K. Jimnisha, V. A. Ayisha, and R. Reghunath, "Landslide susceptibility modelling using integrated evidential belief function based logistic regression method: a study from southern western ghats, India," Remote
Sensing Applications: Society and Environment, Society and Environment, vol. 20, Article ID 100411, 2020.

[49] D. Mafi-Gholami, E. K. Zenner, A. Jaafari, H. R. Riyahi Bakhtyari, and D. Tien Bui, "Multi-hazards vulnerability assessment of southern coasts of Iran," Journal of Environmental Management, vol. 252, Article ID 109628, 2019.

[50] D. Mafi-Gholami, E. K. Zenner, A. Jaafari, and D. T. Bui, "Spatially explicit predictions of changes in the extent of mangroves of Iran at the end of the 21st century," Estuarine, Coastal and Shelf Science, vol. 237, Article ID 106644, 2020.

[51] P. Tsangaratos, I. Ilia, H. Hong, W. Chen, and C. Xu, "Applying information theory and GIS-based quantitative methods to produce landslide susceptibility maps in Nancheng county, China," Landslides, vol. 14, no. 3, pp. 1091-1111, 2017.

[52] L. Wang, Y. Peng, Y. Xie, B. Chen, and Y. Du, "A new iteration regularization method for dynamic load identification of stochastic structures," Mechanical Systems and Signal Processing, vol. 156, Article ID 107586, 2021.

[53] D. Yu, Y. Mao, B. Gu, S. Nojavan, K. Jermsittiparsert, and M. Nasseri, "A new LQG optimal control strategy applied on a hybrid wind turbine/solid oxide fuel cell/in the presence of the interval uncertainties," Sustainable Energy, Grids and Networks, vol. 21, Article ID 100296, 2020.

[54] V. H. Nhu, A. Mohammadi, H. Shahabi et al., "Monitoring and assessment of water level fluctuations of the lake urmia and its environmental consequences using multitemporal landsat 7 ETM + images," International Journal of Environmental Research and Public Health, vol. 17, no. 12, p. 4210, 2020.

[55] R. M. Adnan, A. Jaafari, A. Mohanavelu, O. Kisi, and A. Elbeltagi, "Novel ensemble forecasting of streamflow using locally weighted learning algorithm," Sustainability, vol. 13, no. 11, p. 5877, 2021.

[56] S. Pirasteh, E. K. Zenner, D. Mafi-Gholami et al., "Modeling mangrove responses to multi-decadal climate change and anthropogenic impacts using a long-term time series of satellite imagery," International Journal of Applied Earth Observation and Geoinformation, vol. 102, Article ID 102390, 2021.

[57] J. Zhang, M. Wang, Y. Tang et al., "Angular velocity measurement with improved scale factor based on a widebandtunable optoelectronic oscillator," IEEE Transactions on Instrumentation and Measurement, vol. 70, pp. 1-9, 2021.

[58] C. Zhang and H. Wang, "Swing vibration control of suspended structure using active rotary inertia driver system: parametric analysis and experimental verification," Applied Sciences, vol. 9, no. 15, p. 3144, 2019.

[59] A. Jaafari, S. V. Razavi Termeh, and D. T. Bui, "Genetic and firefly metaheuristic algorithms for an optimized neuro-fuzzy prediction modeling of wildfire probability," Journal of Environmental Management, vol. 243, pp. 358-369, 2019.

[60] L. Peng, R. Niu, B. Huang, X. Wu, Y. Zhao, and R. Ye, "Landslide susceptibility mapping based on rough set theory and support vector machines: a case of the Three Gorges area, China," Geomorphology, vol. 204, pp. 287-301, 2014.

[61] A. Jaafari, "LiDAR-supported prediction of slope failures using an integrated ensemble weights-of-evidence and analytical hierarchy process," Environmental Earth Sciences, vol. 77, no. 2, 2018.

[62] B. T. Pham, T. V. Phong, M. Avand et al., "Improving voting feature intervals for spatial prediction of landslides," Mathematical Problems in Engineering, vol. 2020, Article ID 4310791, 15 pages, 2020. 
[63] R.-X. Tang, P. H. S. W. Kulatilake, E.-C. Yan, and J.-S. Cai, "Evaluating landslide susceptibility based on cluster analysis, probabilistic methods, and artificial neural networks," Bulletin of Engineering Geology and the Environment, vol. 79, no. 5, pp. 2235-2254, 2020.

[64] Y. Yang, C. Hou, Y. Lang, T. Sakamoto, Y. He, and W. Xiang, "Omnidirectional motion classification with monostatic radar system using micro-doppler signatures," IEEE Transactions on Geoscience and Remote Sensing, vol. 58, no. 5, pp. 3574-3587, 2019.

[65] S. Lee and B. Pradhan, "Landslide hazard mapping at Selangor, Malaysia using frequency ratio and logistic regression models," Landslides, vol. 4, no. 1, pp. 33-41, 2007.

[66] M. Mehrabi, B. Pradhan, H. Moayedi, and A. Alamri, "Optimizing an adaptive neuro-fuzzy inference system for spatial prediction of landslide susceptibility using four state-of-theart metaheuristic techniques," Sensors, vol. 20, no. 6, p. 1723, 2020.

[67] S. Segoni, V. Tofani, D. Lagomarsino, and S. Moretti, "Landslide susceptibility of the pplt," Journal of Maps, vol. 12, no. 1, pp. 401-406, 2016.

[68] S. Shabani, A. Jaafari, and P. Bettinger, "Spatial modeling of forest stand susceptibility to logging operations," Environmental Impact Assessment Review, vol. 89, Article ID 106601, 2021.

[69] E. Nohani, M. Moharrami, S. Sharafi et al., "Landslide susceptibility mapping using different GIS-based bivariate models," Water, vol. 11, no. 7, p. 1402, 2019.

[70] J. Yu and Q. Liu, "Larix olgensis growth-climate response between lower and upper elevation limits: an intensive study along the eastern slope of the Changbai mountains, northeastern China," Journal of Forestry Research, vol. 31, no. 1, pp. 231-244, 2020.

[71] B. T. Pham, T. V. Phong, M. Avand et al., "Improving voting feature intervals for spatial prediction of landslides," Artificial Intelligence for Civil Engineering, vol. 2020, Article ID 4310791, 15 pages, 2020.

[72] M. Bayat, M. Ghorbanpour, R. Zare, A. Jaafari, and B. Thai Pham, "Application of artificial neural networks for predicting tree survival and mortality in the Hyrcanian forest of Iran," Computers and Electronics in Agriculture, vol. 164, 2019.

[73] D. Q. Thanh, D. H. Nguyen, I. Prakash et al., "GIS based frequency ratio method for landslide susceptibility mapping at Da Lat city, Lam Dong province, Vietnam," Vietnam Journal of Earth Sciences, vol. 42, no. 1, pp. 55-66, 2020.

[74] V.-H. Nhu, S. Janizadeh, M. Avand et al., "GIS-based gully erosion susceptibility mapping: a comparison of computational ensemble data mining models," Applied Sciences, vol. 10, no. 6, p. 2039, 2020.

[75] K. Zhang, Q. Wang, L. Chao et al., "Ground observationbased analysis of soil moisture spatiotemporal variability across a humid to semi-humid transitional zone in China," Journal of Hydrology, vol. 574, pp. 903-914, 2019.

[76] A. Jaafari, A. Najafi, H. R. Pourghasemi, J. Rezaeian, and A. Sattarian, "GIS-based frequency ratio and index of entropy models for landslide susceptibility assessment in the Caspian forest, northern Iran," International journal of Environmental Science and Technology, vol. 11, no. 4, pp. 909-926, 2014.

[77] A. Jaafari, J. Rezaeian, and M. S. Omrani, "Spatial prediction of slope failures in support of forestry operations safety," Croatian Journal of Forest Engineering, vol. 38, no. 1, pp. 107-118, 2017.

[78] A. Jaafari, A. Najafi, J. Rezaeian, A. Sattarian, and I. Ghajar, "Planning road networks in landslide-prone areas: a case study from the northern forests of Iran," Land Use Policy, vol. 47, pp. 198-208, 2015.

[79] B. T. Pham, I. Prakash, A. Jaafari, and D. T. Bui, "Spatial prediction of rainfall-induced landslides using aggregating one-dependence estimators classifier," Journal of the Indian Society of Remote Sensing, vol. 46, no. 9, pp. 1457-1470, 2018.

[80] A. Jaafari, A. Najafi, J. Rezaeian, and A. Sattarian, "Modeling erosion and sediment delivery from unpaved roads in the north mountainous forest of Iran," GEM-International Journal on Geomathematics, vol. 6, no. 2, pp. 343-356, 2015.

[81] M. H. Nami, A. Jaafari, M. Fallah, and S. Nabiuni, "Spatial prediction of wildfire probability in the Hyrcanian ecoregion using evidential belief function model and GIS," International journal of Environmental Science and Technology, vol. 15, no. 2, pp. 373-384, 2018.

[82] D. T. Bui, P.-T. T. Ngo, T. D. Pham et al., "A novel hybrid approach based on a swarm intelligence optimized extreme learning machine for flash flood susceptibility mapping," Catena, vol. 179, pp. 184-196, 2019.

[83] P. T. Nguyen, D. H. Ha, M. Avand et al., "Soft computing ensemble models based on logistic regression for groundwater potential mapping," Applied Sciences, vol. 10, no. 7, p. 2469, 2020.

[84] M. N. Jebur, B. Pradhan, and M. S. Tehrany, "Optimization of landslide conditioning factors using very high-resolution airborne laser scanning (LiDAR) data at catchment scale," Remote Sensing of Environment, vol. 152, pp. 150-165, 2014.

[85] H. Nguyen, M. Mehrabi, B. Kalantar, H. Moayedi, and M. a. M. Abdullahi, "Potential of hybrid evolutionary approaches for assessment of geo-hazard landslide susceptibility mapping," Geomatics, Natural Hazards and Risk, vol. 10, no. 1, pp. 1667-1693, 2019.

[86] H. Shu, M. Hürlimann, R. Molowny-Horas et al., "Relation between land cover and landslide susceptibility in Val d'Aran, Pyrenees (Spain): historical aspects, present situation and forward prediction," The Science of the Total Environment, vol. 693, Article ID 133557, 2019.

[87] S. Ghosh, E. J. M. Carranza, C. J. van Westen, V. G. Jetten, and D. N. Bhattacharya, "Selecting and weighting spatial predictors for empirical modeling of landslide susceptibility in the Darjeeling Himalayas (India)," Geomorphology, vol. 131, no. 1, pp. 35-56, 2011.

[88] R. Anbalagan, "Landslide hazard evaluation and zonation mapping in mountainous terrain," Engineering Geology, vol. 32, no. 4, pp. 269-277, 1992.

[89] B. T. Pham, A. Shirzadi, H. Shahabi et al., "Landslide susceptibility assessment by novel hybrid machine learning algorithms," Sustainability, vol. 11, no. 16, p. 4386, 2019.

[90] Y.-C. Chuang and Y.-S. Shiu, "Relationship between landslides and mountain development-integrating geospatial statistics and a new long-term database," The Science of the Total Environment, vol. 622-623, pp. 1265-1276, 2018.

[91] D. Tien Bui, Q. P. Nguyen, N.-D. Hoang, and H. Klempe, “A novel fuzzy K-nearest neighbor inference model with differential evolution for spatial prediction of rainfall-induced shallow landslides in a tropical hilly area using GIS," Landslides, vol. 14, no. 1, pp. 1-17, 2017.

[92] L. Sun, C. Li, C. Zhang, T. Liang, and Z. Zhao, "The strain transfer mechanism of fiber Bragg grating sensor for extra large strain monitoring," Sensors, vol. 19, no. 8, p. 1851, 2019.

[93] P. Yariyan, S. Janizadeh, T. Van Phong et al., "Improvement of best first decision trees using bagging and dagging ensembles for flood probability mapping," Water Resources Management, vol. 34, no. 9, pp. 3037-3053, 2020. 
[94] S. Qu, W. Xu, J. Zhao, and H. Zhang, "Design and implementation of a fast sliding-mode speed controller with disturbance compensation for SPMSM syste," IEEE Transactions on Transportation Electrification, 2021.

[95] J. L. M. da Silva, F. V. Mendes, and R. V. Ramos, "Radial basis function network using Lambert-Tsallis Wq function," Physica A: Statistical Mechanics and Its Applications, vol. 534, Article ID 122168, 2019.

[96] B. Postance, J. Hillier, T. Dijkstra, and N. Dixon, "Extending natural hazard impacts: an assessment of landslide disruptions on a national road transportation network," Environmental Research Letters, vol. 12, no. 1, Article ID 014010, 2017.

[97] M. Juliev, M. Mergili, I. Mondal, B. Nurtaev, A. Pulatov, and J. Hübl, "Comparative analysis of statistical methods for landslide susceptibility mapping in the Bostanlik district, Uzbekistan," The Science of the Total Environment, vol. 653, pp. 801-814, 2019.

[98] S. P. Pradhan and T. Siddique, "Stability assessment of landslide-prone road cut rock slopes in Himalayan terrain: a finite element method based approach," Journal of Rock Mechanics and Geotechnical Engineering, vol. 12, no. 1, pp. 59-73, 2020. 